\title{
O ENSINO DE FUNÇÕES EXPONENCIAIS POR ENGRENAGENS ROBÓTICAS
}

\section{TEACHING EXPONENTIAL FUNCTIONS THROUGH ROBOTICS GEARS}

\author{
Fernando Kennedy da Silva \\ Universidade Federal de Catalão, Brasil \\ fernando.kennedy.silva@ufg.br \\ Cristhian Pires da Costa \\ Escola Estadual Coronel Elmiro Alves do Nascimento, Brasil \\ cristhianpires@hotmail.com
}

\begin{abstract}
RESUMO: O tema central deste trabalho é a função exponencial e a do tipo exponencial através de interações entre engrenagens do Kit LEGO ${ }^{\circledR}$ Mindstorms NXT. Para isso, utilizamos a construção de um carrinho com peças do kit, composto por um câmbio de quatro marchas, que funcionam sob uma taxa de variação exponencial. A motivação deste trabalho foi descobrir se seria possível ou não abstrair essa função, a partir de interações entre engrenagens, que, em sua grande maioria, são associadas apenas às questões de proporcionalidade e, consequentemente, a funções lineares. Mas, com análises e estudos feitos em materiais já produzidos, tanto sobre interações entre engrenagens, como sobre câmbios de marchas feitos de peças LEGO $_{\circledast}$, conseguimos efetuar a construção do câmbio proposto. Utilizamo-nos de reduções de giros nas engrenagens, que, em sequência, formaram uma progressão geométrica, a qual, por sua vez, foi associada à função do tipo exponencial. Assim, esse câmbio é utilizado como objeto de estudo de uma sequência didática e de conteúdos, tanto no que diz respeito a sua construção como quanto a seu funcionamento. Como resultados deste trabalho, primeiro é possível vislumbrar o grande acervo matemático existente nas interações entre engrenagens, o que, quando associado à Robótica Educacional, permite trabalhar de forma plena o desenvolvimento integral dos alunos, e segundo, uma sequência didática para o ensino da função exponencial, que parte da construção concreta de algo, para a abstração matemática.
\end{abstract}

PALAVRAS-CHAVE: Engrenagens. Função exponencial. LEGO ${ }^{\circledR}$. Sequência didática. Robótica educacional.

ABSTRACT: The central theme of this work is the exponential function and the exponential type through interactions between gears of the LEGO ${ }^{\circ}$ Mindstorms NXT Kit. For this, we used the construction of a cart with parts from the kit, composed of a 4-speed gearbox, which works under an exponential rate of change. The motivation of this work was to discover if it would be possible or not to abstract this function, from interactions between gears that, in the great majority, are only associated with the proportionality issues and, consequently, with linear functions. But, with analyzes and studies made on materials already obtained, both on interactions between gears and on gear changes made of LEGO ${ }^{\circledR}$ pieces, we could carry out the construction of the proposed gear. We use gears reductions, which, in sequence, form a geometric progression, which, in turn, was associated with the exponential type function. Thus, this exchange is used as an object of study of a didactic sequence and content, both with regard to its construction and its 
functioning. And as a result of this work, first it is possible to glimpse the great mathematical collection existing in the interactions between gears, which, when associated with Educational Robotics, allows us to fully work on the integral development of students, and second, a didactic sequence for teaching exponential function, which starts from the concrete construction of something, for mathematical abstraction.

KEYWORDS: Gears. Exponential function. LEGO®. Didactic sequence. Educational robotics.

\section{Introdução}

A função exponencial, conteúdo abordado no primeiro ano do ensino médio na disciplina de matemática, está presente em várias situações do cotidiano, como nos juros cobrados em cartões de crédito, ou no número de novas pessoas infectadas por uma doença, sob uma taxa de transmissão constante. Essa função também possui aplicabilidade em diversas áreas, como na arqueologia, economia, biologia, física, engenharias etc. O seu papel é sempre importante ao caracterizar um tipo de crescimento ou decrescimento específico, em que a taxa de variação não é constante como na linear, mas proporcional. Costuma-se dizer que tal função apresenta um comportamento "explosivo", pelo seu rápido crescimento ou decréscimo. Por exemplo: Se são oferecidas a uma pessoa duas opções financeiras: 1 milhão de reais no último dia do próximo mês ou 1 real no primeiro dia do próximo mês com a condição de dobrar tal valor a cada dia até o último do mês, qual seria a escolha mais vantajosa financeiramente para ela?

Nesse exemplo, é levado em consideração o acentuado crescimento caracterizado como exponencial, pois, apesar de 1 milhão de reais ser bem maior que 1 real, como esse último valor é sempre dobrado, no vigésimo primeiro dia do mês ele já terá ultrapassado 1 milhão.

Esse crescimento exponencial representa uma parte de todo o conteúdo que envolve a função em si, assim como a característica de transformar produtos em soma, ou ainda a representação da curva catenária e os juros cobrados em transações financeiras pelos bancos (os juros compostos) e diversas outras situações cotidianas e também complexas, como o número de infectados em uma pandemia conforme uma determinada taxa de transmissão.

Esse último tema, pandemia, tem sido bastante discutido no Brasil e no mundo neste ano (2020), devido à pandemia da doença COVID-19. A título de exemplo, suponha que a taxa de transmissão dessa doença, por pessoa, seja de 3 durante determinado tempo, ou seja, uma pessoa infectada transmite a doença para mais três pessoas. Desse modo, de início temos 1 infectado, este transmite para 3 pessoas, essas 3 pessoas seguindo a mesma taxa de transmissão - irão transmitir para 9 pessoas, essas 9 , para 27, e assim por diante, formando então uma progressão geométrica do número de novos infectados, neste exemplo, a progressão: $1,3,9,27 \ldots$ Observe que o crescimento dos valores desse tipo de progressão é muito rápido, característica já citada da função exponencial.

Portanto, a aplicabilidade dessa função em diversas áreas e suas características específicas (crescimento ou decréscimo explosivos, transformação de produto em soma) foram fatores motivadores para a escolha deste tema. E, consequentemente, ficou escolhido também o público-alvo, uma vez que seu ensino na educação básica ocorre no 
nível médio, frequentemente no primeiro ano, conforme orienta a Base Nacional Comum Curricular (BRASIL, 2017).

Escolhidos, então, o tema e o público, a questão passou a ser como trabalhar esse tema, pois era necessário encontrar uma forma de abordar a função exponencial que despertasse interesse dos alunos, motivando-os a querer entender seu comportamento e suas aplicabilidades e, além disso, que instigasse o professor a se capacitar ainda mais para o conteúdo. Com isso, pretendia-se que, de certa forma, houvesse a abstração da função para que o aluno tivesse a percepção dela a partir de sua passagem do concreto para o abstrato, e que ao mesmo tempo isso fosse feito de maneira atual.

Desse ponto de vista, seguindo esses anseios, escolhemos abordar o tema utilizando tecnologia, o que foi feito com embasamento, sob o viés do aprender fazendo, instruído por Papert (1980), assim como aproveitando sua indicação do uso de engrenagens como forma eficiente para o ensino de matemática, Papert (1985). Para tanto, optamos pela utilização do Kit LEGO ${ }^{\circledR}$ Mindstorms NXT.

No intuito, então, de associar a robótica por meio do Kit LEGO ${ }^{\circledR}$ com a função exponencial, mediante interações entre engrenagens, chegamos à pergunta norteadora deste trabalho: seria possível abstrair a função exponencial de interações entre engrenagens LEGO $^{\circledR}$ e, com essas interações, construir um câmbio de marchas que possa ser objeto de estudo em uma sequência didática para auxílio no ensino da função exponencial?

Desse modo, o objetivo principal deste trabalho é a abstração da função exponencial, por meio do funcionamento de um câmbio de 4 marchas, construído com o Kit LEGO ${ }^{\circledR}$ Mindstorms NXT, sendo este, objeto de estudo da sequência didática, apresentada como um recurso para o ensino da função exponencial, por meio de estudo e exploração de interações entre engrenagens, o que já fora mencionado por Papert (1985), conforme apresentamos a seguir.

\section{Papert: as engrenagens de minha infância}

Segundo relata em seu livro, Logo: Computadores e Educação [Mindstorms: children, computers and powerfulideas], Papert (1985) teve em sua infância uma relação afetiva com engrenagens como brinquedos. Segundo ele, antes de seus dois anos de idade, já se interessava bastante por automóveis, os nomes das peças que compunham o carro faziam parte de seu vocabulário, e, à medida que foi crescendo, a parte do diferencial nos carros, com as engrenagens que o compõe, tornaram-se sua parte favorita. Brincar com engrenagens era seu melhor passatempo: "Adorava girar objetos uns contra os outros em movimentos circulares e, naturalmente, meu primeiro "projeto de construção" foi um sistema rudimentar de engrenagens" (PAPERT, 1985, p. 11).

Ele associava a relação entre os giros das engrenagens ao que the era ensinado na escola, conseguindo assimilar melhor o entendimento de conteúdos abstratos:

[...] Engrenagens, servindo como modelos, facilitaram o meu acesso a ideias que eram muito abstratas. (...). Eu via as tabuadas como engrenagens, e meu primeiro contato com equações de duas variáveis (por exemplo, $3 x+4 y=10$ ) evocaram imediatamente o diferencial. Quando eu estabelecia um modelo mental de engrenagens para a relação entre $x$ e $y$, imaginando quantos dentes cada uma 
delas necessitava, a equação tornava-se um ser amigável (PAPERT, 1985, p. 1114).

Ao utilizar a expressão "a equação tornava-se um ser amigável", ele reforça um dos pontos de sua preocupação em fazer uma reconstrução pessoal do Construtivismo de Piaget (1978). Os conceitos do Construtivismo são sensos comuns para Papert (1985). Porém, ele aponta uma preocupação sobre o que, segundo ele, não encontrou na teoria de Piaget (1978), o lado afetivo no processo de assimilação de novos conhecimentos.

[...] quando li Piaget, este incidente me serviu como modelo para a noção de assimilação que ele propôs, apesar de ficar muito impressionado pelo fato de sua discussão não fazer justiça total às suas próprias ideias. Ele praticamente só fala sobre os aspectos cognitivos da assimilação, sem levar em conta o componente afetivo. A assimilação de equações em termos de engrenagens é certamente uma maneira poderosa de fazer com que um conhecimento anterior seja relevante à compreensão de um novo assunto. Mas este esquema ainda faz mais. Estou certo que tais assimilações fizeram com que a matemática tivesse, para mim, um caráter afetivo que remonta às experiências com carros durante minha infância (PAPERT, 1985, p. 12).

Portanto, para Papert (1985), assimilar novos conhecimentos implica tomar como base, ou modelo, conhecimentos já adquiridos, tendo relativa importância a maneira como ocorrerá essa aquisição. Assim, ele afirma: "Aos poucos, comecei a formular o que ainda considero o fato fundamental sobre aprendizagem: qualquer coisa é simples se a pessoa consegue incorporá-la ao seu arsenal de modelos; caso contrário tudo pode ser extremamente difícil" (PAPERT, 1985, p. 13).

E assim podemos deduzir duas coisas; a primeira, que temos um ciclo recursivo, pois aprender novos conhecimentos gera um maior acervo de modelos disponíveis na mente, o qual, por sua vez, é utilizado na assimilação de outros novos conhecimentos. Ou seja, quanto mais se aprende, mais se está apto a aprender. E a segunda, que, ao nascer, precisamos de uma bagagem hereditária de conhecimentos para que estes sirvam de iniciais modelos, caso contrário os primeiros aprendizados seriam extremamente difíceis, o que também está em acordo com a teoria de Piaget (1975, p. 326): "[...] em seu início, a assimilação é, essencialmente, a utilização do meio externo, pelo sujeito, tendo em vista alimentar seus esquemas hereditários ou adquiridos".

Associando, então, as ideias de Piaget (1975) com a experiência na infância com as engrenagens, Papert atribui a elas a propriedade de serem eficazes ferramentas no ensino de conteúdos matemáticos:

Os trabalhos de Piaget me deram uma nova perspectiva para olhar as engrenagens de minha infância. Elas podem ser usadas para ilustrar muitas ideias matemáticas poderosas e avançadas, tais como teoria dos grupos ou movimento relativo. Mas elas fazem ainda mais que isso. Assim como as engrenagens estão relacionadas com o conhecimento matemático formal, relacionam-se também com o conhecimento corporal, com o esquema sensório-motor de uma criança. Você pode ser a engrenagem, você pode entender como ela se movimenta projetando seu próprio corpo em seu lugar e girando com ela. E essa dupla relação - tanto abstrata quanto sensorial - é que dá à engrenagem o poder de suscitar inúmeras ideias matemáticas na mente (PAPERT, 1985, p. 13-14). 
E dessa forma, utilizando-nos de interações entre engrenagens (Kit LEGO ${ }^{\circledR}$ Mindstorms NXT), propomos abstrair as funções exponencial e do tipo exponencial, assim como conceitos prévios necessários durante esse processo, a saber, proporcionalidade, função linear, composição de funções, progressões aritméticas e geométricas. Isso associado à Robótica Educacional.

\section{Robótica Educacional}

A utilização do Kit LEGO ${ }^{\circledast}$ (LEGO GROUP) neste trabalho se apresenta de maneira muito eficiente no campo educacional. Como afirma Benitti et al. (2009), "uma forma de viabilizar o conhecimento científico tecnológico e, ao mesmo tempo, estimular a criatividade e a experimentação com um forte apelo lúdico, pode ser proporcionada através da robótica educativa" (BENITTI et al., 2009, p. 1811). E ainda, conforme aponta Morelato:

Com o uso da robótica pedagógica, o aprendiz pode desenvolver a sua capacidade de solucionar problemas, utilizar a lógica de forma eficaz e aprender conceitos ligados a matemática e física. Desta forma se colocam em prática conceitos abordados em sala de aula apenas de maneira teórica e sem conectividade com o mundo real. A Robótica educacional proporciona um ambiente caracterizado pela tecnologia e criatividade, estimulando o aprendizado de conceitos intuitivos, a exemplo da cinemática em física. Este tipo de ambiente favorece o aprendizado construcionista. (MORELATO et al., 2010, p. 81).

Portanto, Morelato et al. (2010) já não apenas apontam as vantagens na utilização da Robótica como meio pedagógico, como também a associam às ideias construcionistas, que têm como base o Construtivismo de Piaget, o qual também é suporte teórico para Zabala (1998) em suas definições de sequências didáticas, utilizadas neste trabalho, e apresentadas a seguir.

\section{Sequência Didática: conceitos}

Conforme Zabala (1998, p. 18), sequências didáticas são: "um conjunto de atividades ordenadas, estruturadas e articuladas para a realização de certos objetivos educacionais, que têm um princípio e um fim conhecidos tanto pelos professores como pelos alunos".

Dessa forma, Zabala (1998) orienta que, para concluir se uma sequência didática está adequada ao seu objetivo, é necessário analisá-la quanto aos seguintes referenciais, além de seus teóricos específicos: atenção à diversidade e à concepção construtivista de Piaget (1978). Isso se justifica porque a construção do conhecimento é algo pessoal, no qual cada indivíduo utiliza o que já possui de modelo para ler e interpretar o que lhe está sendo proposto. Sendo assim, ainda que o que se constrói de conhecimento seja de forma coletiva em uma aula, cada leitura disso é pessoal e singular, pois os modelos prévios de cada aluno foram elaborados durante toda a sua trajetória particular e única até estar ali. Então, ainda segundo o autor, cabe ao professor perceber como essa "leitura 
e construção" está sendo feita por cada um e interferir, quando perceber que esta pode estar acontecendo de forma errônea, e também ajudar, quando ela não estiver fluindo.

\section{Sequência Didática: a abstração da Função Exponencial por meio de interações entre engrenagens}

Esta sequência didática tem como objetivo principal a abstração da função exponencial em meio à construção de um câmbio de 4 marchas, utilizando interações entre engrenagens, conforme já citado neste trabalho (PAPERT, 1985), uma excelente ferramenta no ensino da matemática. Além disso, esta sequência é elaborada sob o viés do aprender fazendo, afinal, "dando-se às crianças boas coisas para se fazer elas poderão 'aprender fazendo' muito melhor do que [aprendiam] antes", (PAPERT, 1980, parte 1).

E assim, para se chegar à função do tipo exponencial, utilizamos progressões geométricas, formadas através de composições de funções lineares, as quais, por sua vez, modelam em linguagem de funções as relações de proporcionalidade existentes entre as interações de engrenagens.

Consideramos, então, como início de nossa sequência didática, uma revisão de proporcionalidade. Que nesta etapa os alunos tenham uma aula expositiva sobre o tema, um momento para levantar dúvidas e resolver situações-problema, na qual os alunos demonstrem a capacidade de aplicação do conceito específico de proporcionalidade, dando prosseguimento assim ao tema função linear e à sequência didática.

Porém, em todo o processo de construção e abstração da função exponencial, será utilizada a questão da proporcionalidade, então, caso ainda persistam dúvidas sobre o tema no decorrer da sequência didática, é sempre importante que o professor que a esteja aplicando retome o tema e sane as possíveis dúvidas.

Como no decorrer do trabalho os conceitos matemáticos abordados, como proporcionalidade, função linear e composição de funções, serão sempre exemplificados já com situações inerentes à construção do câmbio de marchas, utilizando as engrenagens $\mathrm{LEGO}^{\circledR}$, nesta parte de detalhamento da proposta didática, no intuito de ser objetivo e pragmático, não serão demonstradas as relações matemáticas utilizadas no processo de construção. Porém, tais demonstrações podem ser obtidas no trabalho de Pires da Costa (2020), A abstração da Função Exponencial de Interações entre Engrenagens $L E G O \circledR$.

Por fim, ao se utilizar, então, deste instrumento de aprendizado proposto por Zabala (1998) - a sequência didática -, é importante que a sequência contemple atividades que favoreçam o desenvolvimento dos alunos de forma integral, ou seja, que as atividades propiciem o desenvolvimento conceitual, procedimental e atitudinal dos alunos. Logo, ao iniciar a sequência, devem ser apresentados aos alunos os conceitos e procedimentos matemáticos e também os conteúdos atitudinais que serão trabalhados. Como exemplo destes: a cooperação, o trabalho em equipe, o respeito às dificuldades e facilidades de cada um, o cuidado com o material utilizado, como também a manutenção do ambiente em que se está estudando organizado e limpo. O professor deve lembrar sempre aos seus alunos que o direito individual não se sobreponha ao do outro, que seus comportamentos durante as atividades sempre devem estar em conformidade com o 
bem-estar coletivo dos que ali estão. Sobre a avaliação dos conteúdos conceituais e procedimentais, esta ficará a cargo do professor, levando em consideração que cada escola possui seu projeto político-pedagógico e cada professor seu planejamento de distribuição de pontos. Para a sequência, é estimado um total de 7 aulas, com 50 minutos de duração cada, na qual uma aula sempre se dá com a condição de que a anterior já tenha sido desenvolvida. E se faz necessário um Kit LEGO ${ }^{\circledR}$ NXT para cada grupo de no máximo cinco alunos, visto que grupos maiores podem gerar ociosidade entre eles, acarretando certa dispersão.

\section{Primeira Aula}

Como o conceito de proporcionalidade já é introduzido para o aluno desde os primeiros anos do ensino fundamental II (sexto ao nono ano), não se faz necessária uma introdução profunda e muito técnica do tema. Basta exemplificar situações de proporcionalidade no próprio dia a dia do aluno, como o preço a ser pago por determinado produto vendido pelo seu peso, ou o tempo gasto em uma viagem a uma velocidade média específica e em outra menor ou maior.

Esses exemplos corriqueiros são importantes para que, antes de associar proporcionalidade às interações de engrenagens, que é algo relativamente novo para o aluno, ele perceba a ideia de proporcionalidade e o quanto ela pode ser interpretada de maneira simples em situações comuns.

Após o entendimento da ideia de proporção, e verificada a capacidade de resolver problemas pertinentes a esse conteúdo, é hora de introduzir as engrenagens e suas interações. A Figura 1 apresenta alguns modelos de engrenagens presentes no Kit LEGO ${ }^{\circledR} \mathrm{NXT}$ :

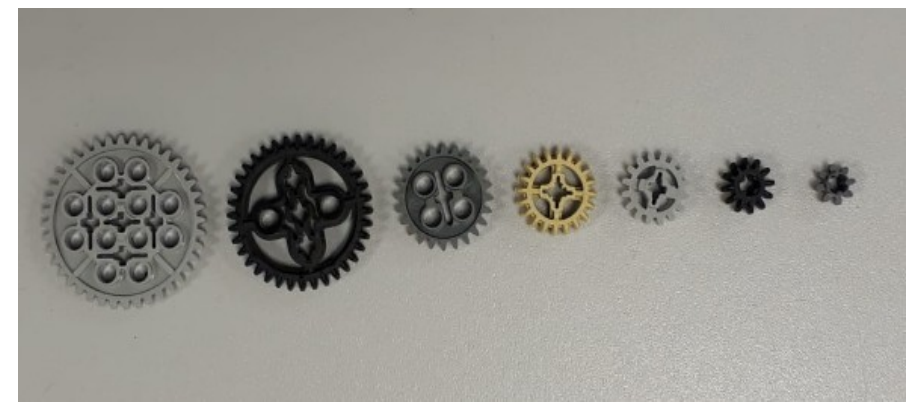

Figura 1: Modelos de engrenagens, KIT LEGO®. Fonte: dos autores.

Como pode ser notado, as engrenagens diferem umas das outras apenas pelo número de dentes e, consequentemente, pelo raio. Mas o tamanho isolado de cada dente em cada engrenagem é sempre o mesmo. Isso implica que, independentemente de quais engrenagens participem de uma interação, um dente sempre se encaixará e moverá apenas um dente também. Dessa maneira, criam-se as relações de proporcionalidade entre as quantidades de giros.

Então, é nesse momento que o aluno deve ter o primeiro contato com as engrenagens. Até então, se fazem necessárias apenas as engrenagens a serem 
utilizadas e as peças que funcionam como eixo e suporte das engrenagens, para que os alunos consigam montar, nesse momento, trens entre duas engrenagens como os modelos de combinações abaixo (Figura 2):

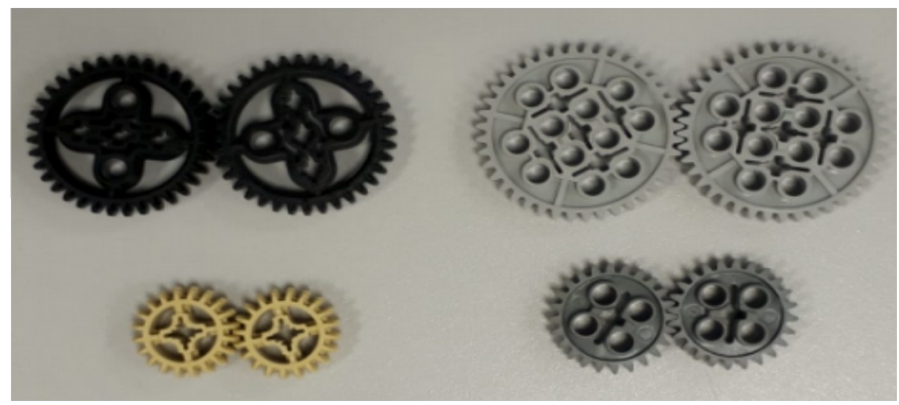

Figura 2: Modelos de interações entre engrenagens, KIT LEGO®.

Fonte: dos autores.

Observe que nos primeiros exemplos as interações foram feitas entre duas engrenagens iguais, o que acarreta uma relação de identidade entre o número de giros das duas engrenagens. Porém não devem ser utilizadas, durante essa etapa, funções lineares; o momento deve se limitar apenas ao entendimento numérico da quantidade de giros.

É importante que o professor instigue os alunos a perceberem que, apesar de a quantidade de giros ser a mesma, os sentidos dos giros serão contrários. Após essa percepção, acopla-se mais uma engrenagem ao sistema, para que seja percebido que o sentido da última engrenagem voltou a ser o mesmo da primeira. E assim devem ser conduzidos à generalização de que, se um sistema apresenta um número par de engrenagens, o sentido da última será o contrário do sentido da primeira, e quando esse número de engrenagens for ímpar, o sentido da primeira e da última engrenagem será o mesmo.

Terminada essa parte, antes de fazer interações entre engrenagens diferentes, é necessário propor um exemplo cotidiano de proporcionalidade, mas que, posteriormente, possa ser remodelado por interações de engrenagens. Por exemplo: Em uma confeitaria, 24 quilos de uma determinada massa são suficientes para fazer 3 bolos. Portanto, para fazer 9 bolos, seguindo o mesmo padrão mencionado, serão necessários quantos quilos de massa? Deve-se esperar que os alunos resolvam a questão e, em seguida, mostrar a seguinte interação: Uma engrenagem de 24 dentes, acoplada a uma engrenagem de 8 dentes (Figura 3). Primeiro pergunta-se quantas voltas a engrenagem de 8 dentes dará quando a de 24 dentes der uma. Espera-se a resposta correta e, após ela, pergunta-se, então, quantas voltas da engrenagem de 24 dentes serão necessárias para que a de 8 dentes dê 9 voltas. Nesse momento, instigue os alunos a perceberem a semelhança contida nos dois exercícios, ainda que em contextos totalmente diferentes. Mais importante nesse momento que a demonstração do teorema de proporcionalidade ou uma resolução algébrica rigorosamente correta pela perspectiva matemática, é que o aluno adquira em seu pensamento a ideia de proporcionalidade, a qual, se bem destacada pelo professor, em situações corriqueiras cotidianas do aluno, permite que este possa vir a apropriar-se do conceito de forma empírica. 


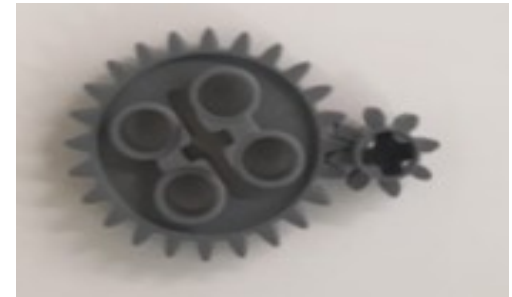

Figura 3: Engrenagens de 24 dentes e 8 dentes, KIT LEGO®. Fonte: dos autores.

Após os alunos terem percebido a proporcionalidade existente nas interações entre engrenagens, propõem-se exercícios que explorem essa questão. É necessário utilizar exercícios nos quais eles descubram determinado número de voltas de uma engrenagem específica, mas também exercícios em que, a partir de uma relação de proporcionalidade, eles tenham de montar o trem de engrenagem (estrutura composta por duas ou mais engrenagens que interagem entre si) que a contenha.

Por exemplo: Construa um trem de engrenagem simples (com apenas duas engrenagens) de forma que o giro de uma resulte em 7 giros da outra. Resposta: A engrenagem à esquerda, com 56 dentes na parte externa, está acoplada a outra de 8 dentes (Figura 4). Portanto, uma razão de proporcionalidade igual a 7, ou seja, cada volta da primeira corresponde a 7 voltas da segunda.

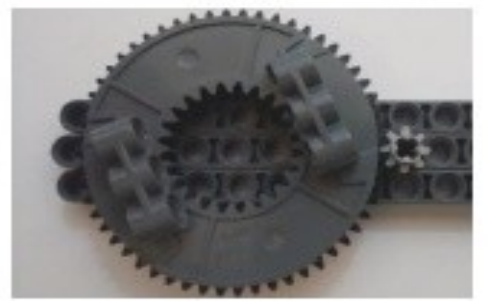

Figura 4: Engrenagens de 56 dentes externos e de 8 dentes, KIT LEGO ${ }^{\circledR}$.

Fonte: Silva, 2014.

Para incrementar esse tipo de exercício, deve-se utilizar relações de giros não tão simples, como: Construa um trem de engrenagem simples (com apenas duas engrenagens) de forma que dois giros de uma, resulte em 9 giros da outra. Resposta: A engrenagem à direita possui 36 dentes, enquanto a da esquerda, 8 dentes. Portanto, uma relação de proporcionalidade de 9/2 (Figura 5).

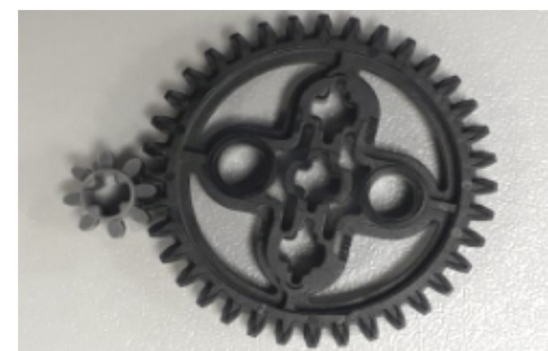

Figura 5: Engrenagens de 36 dentes e 8 dentes, KIT LEGO®.

Fonte: dos autores. 
Até o momento apontamos apenas relações em que a quantidade de giros é ampliada, pois a primeira engrenagem a ser analisada sempre apresentava maior quantidade de dentes em relação à segunda. Algo intencional, uma vez que entender essas relações quando a constante de proporcionalidade é maior que 1 é notavelmente mais fácil. Porém, o câmbio a ser construído apresentará redução de giros e não ampliação. Portanto, é importante também optar por situações-problema em que ocorra redução. Como exemplo: Construa um trem de engrenagem simples (com apenas duas engrenagens) de forma que 5 giros de uma, resulte em apenas 1 giro da outra. Resposta: A engrenagem à direita possui 8 dentes, enquanto a da esquerda, 40 dentes (Figura 6). Portanto, uma razão de proporcionalidade de $1 / 5$. Ou seja, a cada 5 voltas da primeira, apenas 1 volta da segunda.

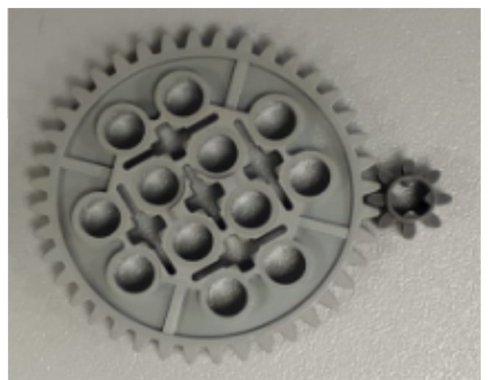

Figura 6: Engrenagens de 8 dentes e 40 dentes, KIT LEGOß. Fonte: dos autores.

O câmbio a ser construído, por questões de disponibilidade do número de peças em cada kit, terá reduções de 1/3 de voltas a cada interação de trem de engrenagens, utilizando engrenagem com 8 dentes acoplada a outra de 24 dentes. É necessário utilizar também esse modelo de redução como exercício, para já facilitar posteriormente o entendimento do funcionamento do câmbio.

\section{Segunda Aula}

Após o entendimento das relações de proporcionalidade entre as engrenagens, é hora de formalizar o conceito através da função linear. Visto que estas são, de forma oportuna pelo grau de complexidade relativamente baixo, já é possível partir para a modelagem da proporcionalidade por função linear de forma mais direta. Como exemplo: Seja o número de voltas $x$ que determinada engrenagem dê, quando acoplada a outra engrenagem. O número de voltas sofrido por esta será representado por $f(x)$, tendo assim uma função, $f: R+\rightarrow R+, \quad a \in R+$, e que por se tratar de uma relação de proporcionalidade, $f(x)=a x$, e, ainda, a sendo ao mesmo tempo a taxa de variação da função linear, como também e por isso, o fator de proporcionalidade entre as engrenagens.

Nesse momento, é relevante explicar o motivo de o domínio ser os reais positivos, afinal o número de voltas não poderá ser nulo ou negativo, não necessariamente sendo um número inteiro, ou racional, mas podendo ser até mesmo irracional, para garantia da continuidade de função. 
Nessa parte, deve ser proposto aos alunos, resolução de exercícios semelhantes aos já trabalhados pela proporcionalidade, mas, nessa etapa, com modelagem e resolução utilizando-se funções lineares. As interações podem ser representadas por funções lineares, pelo fato de satisfazerem as condições que essas funções caracterizam. Deve, agora, ser iniciada a aplicação de exercícios, semelhantes ao abaixo exemplificado:

1. Conforme mostrado no modelo de interação entre engrenagens abaixo (Figura 7), uma engrenagem com 8 dentes está acoplada a outra de 24 dentes.

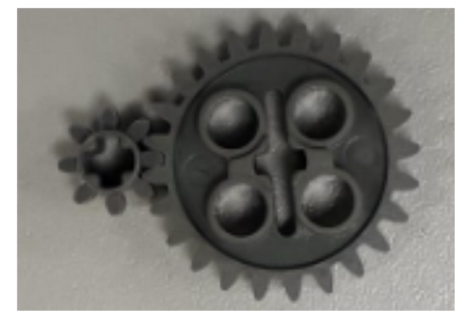

Figura 7: Engrenagens de 8 dentes e 24 dentes, KIT LEGO®. Fonte: dos autores.

Sendo assim, responda:

a) De acordo com a constante de proporcionalidade, considerando que a engrenagem motora seja a de oito dentes e a movida a de 24 . $E$ ainda, sendo $x$ o número de giros da engrenagem motora e $f(x)$ o número de giros sofridos pela movida. Qual função linear modela essa interação? Resolução: Seja $\mathrm{E}_{8}$ a engrenagem motora de oito dentes e $E_{24}$ a engrenagem movida de 24 . Temos assim, a seguinte relação de proporcionalidade:

$\frac{E_{8}}{E_{24}}=\frac{8}{24}=\frac{1}{3}$

Portanto, sendo $1 / 3$ a constante de proporcionalidade, segue-se que:

$$
E_{8} \rightarrow E_{24,} \quad x \rightarrow \frac{1}{3} x .
$$

Ou seja, a função linear que modela a interação é: $f: R+\rightarrow R+, f(x)=\frac{1}{3} x, x \in R+$.

b) Utilizando a função linear que modela a interação, responda quantos giros a engrenagem movida sofrerá, quando a motora girar 81 vezes seguidas. Resolução: Seja $x=81$, temos:

$$
f(x)=\frac{1}{3} x \Rightarrow f(81)=\frac{1}{3} 81=\frac{81}{3}=27 .
$$

Portanto, a engrenagem movida sofrerá 27 giros.

c) Utilizando a função linear que modela a interação, responda quantos giros a engrenagem motora precisa ter dado para que a engrenagem movida tenha dado 9 giros. Resolução: Seja $f(x)=9$, temos:

$f(x)=\frac{1}{3} x \Longrightarrow 9=\frac{1}{3} \cdot x \Longrightarrow 9=\frac{x}{3} \Longrightarrow \frac{27}{3}=\frac{x}{3} \Longrightarrow x=27$.

Portanto, a engrenagem motora teria girado 27 vezes seguidas. 
A seguir devem ser propostos exercícios semelhantes a esse para fixação e melhor entendimento do que foi feito. A princípio, é ideal trabalhar com resultados inteiros para uma compreensão mais fácil, porém, ao notar maior entendimento, é importante trabalhar também com resultados racionais não inteiros e até mesmo irracionais.

\section{Terceira Aula}

Partindo agora para a composição de funções, é importante ressaltar que, assim como as funções lineares, a composição também é esperada como conceito prévio dos alunos, afinal serão utilizadas composições apenas entre funções lineares. E essa específica associação de composições de funções e interações entre trens de engrenagens compostos ocorre quando possuem mais de duas engrenagens.

Inicie apresentando para os alunos, duas interações entre duas engrenagens a princípio separadas, por exemplo: A interação $E_{24} \rightarrow E_{8}$ (Figura 8) e a interação $E_{56} \rightarrow E_{8}$ (Figura 9):

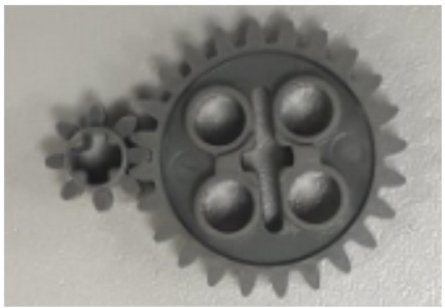

Figura 8: Engrenagens de 24 dentes e 8 dentes, KIT LEGO ${ }^{\circledR}$. Fonte: dos autores.

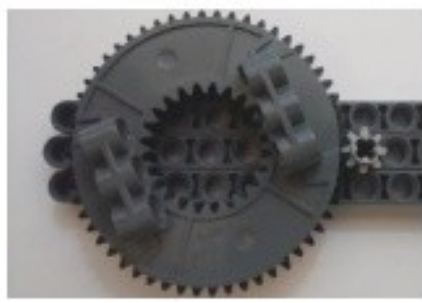

Figura 9: Engrenagens de 56 dentes externos e de 8 dentes, KIT LEGO®. Fonte: Silva, 2014.

A primeira interação $E_{24} \rightarrow E_{8}$ apresenta uma constante de proporcionalidade 3, consequentemente modelada pela função linear, $f(x)=3 x$, enquanto a interação $E_{56} \rightarrow E_{8}$, apresenta a constante de proporcionalidade igual a 7 , portanto $g(x)=7 x$. Então conduza os alunos a criar formas de conectar os dois trens de engrenagem, ligando, por exemplo, por meio do mesmo eixo, a engrenagem de oito dentes da segunda interação com a engrenagem de 24 dentes da primeira, conforme modelo abaixo (Figura 10): 
Figura 10: Trem composto de engrenagens, KIT LEGO®. Fonte: dos autores.

Primeiro, é importante destacar para os alunos que agora a quantidade de giros que a engrenagem de 8 dentes, acoplada a de 56, der, será a mesma que a de 24 dentes dará, por estarem ligadas pelo mesmo eixo, apresentando o mesmo deslocamento angular, não linear. Isso pode ser feito de forma prática mesmo ou de forma algébrica, a fim de que os alunos percebam que essa relação é representada pela função linear identidade.

Após perceberem a ideia acima, proponha situações-problema que explorem tal ideia, como: Quando a engrenagem de 56 dentes der 1 volta completa, quantas voltas a engrenagem de 8 dentes acoplada à de 24 dará? A resolução não necessita de formalização matemática, o interessante a ser entendido pelos alunos nesta etapa é que: Resolução: Pelo fato de a constante de proporcionalidade entre as engrenagens de $E_{56} \mathrm{e}$ $E_{8}$ ser 7, 1 volta de $E_{56}$ implicará 7 voltas de $E_{8}$; por outro lado, como $E_{8}$ está ligado à $E_{24}$ pelo mesmo eixo, $E_{24}$ nesse momento também dará 7 voltas. $E$ agora, 0 fato de a constante de proporcionalidade entre $E_{24}$ e $\quad E_{8}$ ser igual a 3, implica que uma volta de $E_{24}$ resultará em 3 voltas de $E_{8}$. Como $E_{24}$ dará 7 voltas, $E_{8}$ dará 7 voltas vezes 3 voltas, ou seja, 21 voltas.

Durante a resolução do exercício acima, ou de semelhantes que o professor em questão proponha, é muito válido tentar instigar os alunos a perceberem que o resultado de voltas é o produto dos fatores de proporcionalidade, para, assim, dar início à associação com composição de funções.

Para formalizar a relação entre composição de funções e interações de trens de engrenagens compostos, é necessário ressaltar a ideia de que a função composta funciona como um "atalho". Quando temos uma relação entre duas grandezas, uma delas tem relação com outra, então a terceira grandeza tem relação direta com uma das duas primeiras, mas indireta com a outra. Essas relações acontecem nos trens de engrenagens compostos, onde interagem mais de duas engrenagens. A função composta faz a ponte entre essas grandezas que teriam uma relação em princípio indireta. Como exemplo, tomemos o trem de engrenagem composto semelhante ao do exercício anterior (Figura 11): 


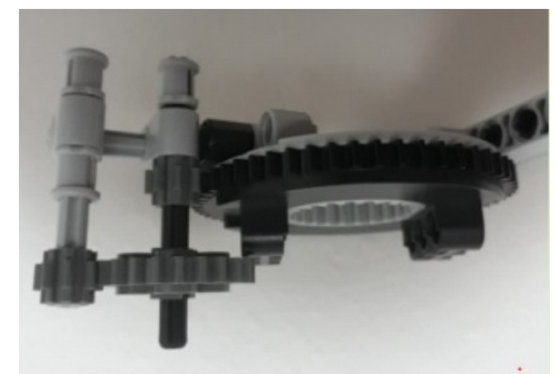

Figura 11: Trem composto de engrenagens, KIT LEGO®. Fonte: dos autores.

A engrenagem de 8 dentes tem relação direta com a de 24, que, por sua vez, tem relação direta com a de 8 , e esta tem relação direta com a de 56 . Sendo assim, a engrenagem de 8 dentes e a de 24, apesar de não estarem acopladas diretamente funcionam de modo que uma transmite ou recebe giros da outra. Portanto, como a engrenagem de 56 dentes, localizada no final, está em função da engrenagem de 8 dentes, a qual, por sua vez, está em função da outra engrenagem de 24, que está em função da engrenagem de 8, temos então uma composição de funções. Para melhor explicação, denotemos por $E_{s}$ a engrenagem de 56 dentes, acoplada a engrenagem de 8 dentes, a última do trem de engrenagens, considerando o sentido da esquerda para a direita, e assim teremos as três funções:

$1^{\text {a }}$ função: interação entre as engrenagens $E_{8}$ e $E_{24}$, modelada como já visto por

$$
f(x)=\frac{1}{3} x
$$

$2^{a}$ função: interação feita pelo mesmo eixo entre as engrenagens $E_{24}$ e $E_{8}$, como já mencionado, modelada por uma função identidade, sendo $g(x)=x$.

$3^{a}$ função: interação feita entre a engrenagem $E_{8}$ e $E_{s}$, modelada, por $h(x)=\frac{1}{7} x$.

A composição de funções lineares é feita da seguinte forma: Primeiro, sendo $f^{\prime}$ a composta $f \circ g$ :

$$
f^{\prime}=f \circ g=f(g(x))=\frac{1}{7} \cdot g(x)=\frac{1}{7} x .
$$

Como podemos observar, por se tratar de uma composição envolvendo uma função identidade, a composta $f \circ g$ é a mesma $f(x)$.

Agora, sendo $h$ 'a composta $f$ ' $\circ$ :

$h^{\prime}=f^{\prime} \circ h=f^{\prime}(h(x))=\frac{1}{7} \cdot h(x)=\frac{1}{7} \cdot \frac{1}{3} x=\frac{1}{21} x$.

Portanto, a função composta que modela a relação de proporcionalidade entre a primeira engrenagem do trem composto, de 8 dentes, e a última, a de 56 dentes é função $h^{\prime}(x)=\frac{1}{21} x$.

De maneira prática, é ideal que os alunos percebam que compor funções lineares nada mais é que ter como resultado, no novo fator de proporcionalidade, o produto dos fatores das funções envolvidas na composição.

Em seguida, deve-se fazer mais alguns exercícios envolvendo composição de 
funções, contudo vamos ressaltar o próximo exemplo: Como percebemos, de forma prática, compor funções lineares é o mesmo que multiplicar os fatores de proporcionalidade das funções envolvidas na composição, resultando em um novo fator e consequentemente em uma nova função. Mas e se essa composição fosse sempre feita com a mesma função, por exemplo, $f(x)$ composta com ela mesma, e essa composição composta com $f(x)$ novamente? Qual seria o resultado? Considerando a função $f(x)=\frac{1}{3} x$ , que modela a interação abaixo (Figura 12):

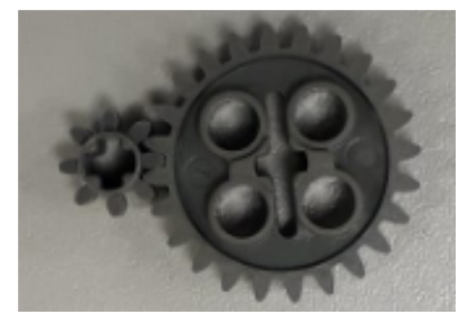

Figura 12: Engrenagem de 8 dentes e de 24 dentes, KIT LEGO® Fonte: dos autores.

Resolução:

$1^{\mathrm{a}}$ interação/composição, seja $\mathrm{f}_{1}$ a composta $f \circ f$, temos:

$$
f_{1}=f(f(x))=\frac{1}{3} f(x)=\frac{1}{3} \frac{1}{3} x=\frac{1}{9} x
$$

Portanto, para a primeira interação entre os dois trens de engrenagem, temos a função composta, $f_{1}(x)=\frac{1}{9} x$.

$2^{\mathrm{a}}$ interação/composição, seja $\mathrm{f}_{2}$ a composta $f_{1} \circ f$, temos:

$f_{2}=f_{1}(f(x))=\frac{1}{9} \cdot f(x)=\frac{1}{9} \cdot \frac{1}{3} x=\frac{1}{27} x$

Portanto, para a segunda interação entre os dois trens de engrenagem, temos a função composta, $f_{2}(x)=\frac{1}{27} x$.

Esse exercício é importante, pois tais reduções são as que serão utilizadas no câmbio de marchas. A saber, a quarta marcha terá o número de giros igual ao número de giros do motor que moverá o câmbio, a terceira terá uma redução de giros em relação ao motor de $1 / 3$, a segunda de $1 / 9$, e a primeira de $1 / 27$, colocando-se, assim, em progressão geométrica as reduções, que serão modeladas por uma função do tipo exponencial. Portanto, é interessante explorar mais exercícios semelhantes a este, utilizando trens compostos de engrenagens e os modelando por funções compostas, para fixação do conteúdo, e se possível deixar atividades para serem feitas pelos próprios alunos. 


\section{Quarta Aula}

Para esta aula são requisitos: conhecimento sobre Progressão Aritmética (PA) e Progressão Geométrica (PG). Sobre PA basta apenas sua identificação através da caracterização de uma; sobre PG é necessário, além de sua identificação, também pela sua caracterização, a interpretação e utilização da sua fórmula do termo geral. A fórmula da soma dos termos de uma PG não será necessária.

A intenção final é a função exponencial, porém a proposta de construção trabalhará apenas com uma relação discreta entre os números de giros das engrenagens; sendo assim, para afirmar que uma relação discreta entre duas grandezas é caracterizada por uma função exponencial, que é definida nos reais para os reais positivos, é necessário recorrer ao teorema no livro do professor Lima (2013): Seja $E_{24} \rightarrow E_{8}$ uma função monótona injetiva (isto é, crescente ou decrescente) que transforma toda progressão aritmética $x_{1}, x_{2}, \ldots, x_{n}, \ldots$ numa progressão geométrica $y_{1}, y_{2}, \ldots, y_{n}, \ldots$, onde $y_{n}=f\left(x_{n}\right)$. Se pusermos $b=f(0)$ e $a=\frac{f(1)}{f(0)}$ teremos $f(x)=b a^{x}$ para todo $x \in R$.

Portanto, pelo teorema, temos que toda função que transforma uma PA em uma $P G$, ainda que em se tratando de um universo de números discretos, é uma função do tipo exponencial, de reais nos reais. Para mostrar isso aos alunos, primeiro, como já dito, é necessário que eles consigam, a princípio, identificar e diferenciar uma PA de uma PG. Então proponha questões simples para que eles trabalhem essa capacidade, caso haja dúvida. Ciente de que não haja, ou sanadas as dúvidas, retoma-se o exemplo do exercício anterior, no qual uma função que modela uma redução de $1 / 3$ no número de giros é composta com ela mesma duas vezes consecutivas. Porém, em seguida, deve ser pedido para que os alunos montem quatro estruturas com o Kit:

$1^{\mathrm{a}}$. Na primeira estrutura é acoplada uma engrenagem de 24 dentes ao final de um eixo, e, no início desse eixo, é acoplado um motor de rotação. Abaixo, a sugestão do modelo de estrutura (Figura 13):

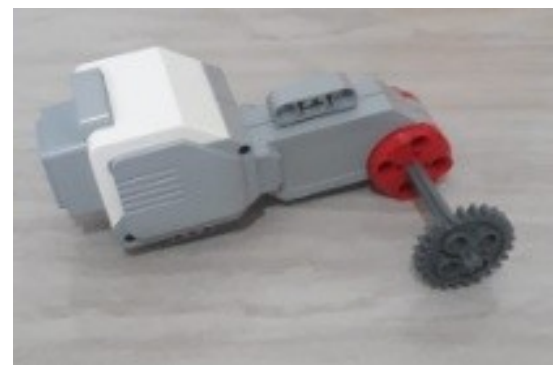

Figura 13: Motor de rotação com engrenagem acoplada, KIT LEGO ${ }^{\circ}$. Fonte: dos autores.

$2^{\mathrm{a}}$. Na segunda, deve ser acoplada ao eixo que sai do motor uma engrenagem de 8 dentes, e esta deve ser acoplada a uma engrenagem de 24 dentes, conforme modelo sugerido abaixo (Figura 14): 
Figura 14: Motor de rotação com engrenagens acopladas, KIT LEGO®.

Fonte: dos autores.

$3^{a}$. Na terceira, seguindo a ideia da segunda, será acoplada ao eixo da de 24 dentes mais uma engrenagem de 8 dentes, que será acoplada em outra engrenagem de 24 dentes, conforme modelo sugerido abaixo (Figura 15):

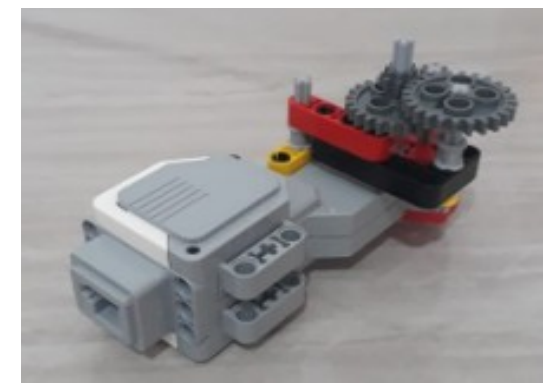

Figura 15: Motor de rotação com engrenagens acopladas, KIT LEGO®. Fonte: dos autores.

$4^{\text {a }}$. Na quarta estrutura, seguindo também a ideia da terceira, será acoplada no mesmo eixo da engrenagem de 24 dentes, colocada por último - ou seja, a que corresponde no momento da terceira estrutura à última engrenagem do trem composto uma engrenagem de 8 dentes, e acoplada a esta haverá outra engrenagem de 24 dentes. Conforme modelo sugerido abaixo (Figura 16):

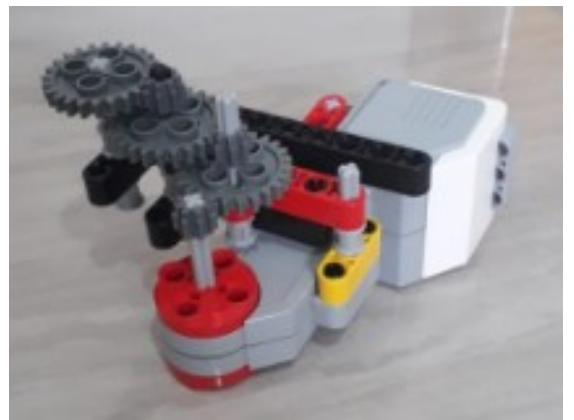

Figura 16: Motor de rotação com engrenagens acopladas, KIT LEGO® Fonte: dos autores.

Feitas as estruturas, vale ressaltar que, apesar de todos os modelos conterem, além da estrutura, o motor de rotação, o motor utilizado pode ser o mesmo para todas, de modo que basta retirá-lo de uma e encaixá-lo na estrutura a ser analisada. Também, posteriormente, analisaremos as quatro interações em apenas uma estrutura.

Nesse momento, inicia-se a análise de cada estrutura e suas interações. Deve ser 
acordado com os alunos, que a referência para formular a função linear para as interações de cada uma será sempre a relação entre o número de giros do motor e a última ou única engrenagem de 24 dentes em cada trem composto ou simples. E para cada estrutura se espera as seguintes conclusões:

- Para a primeira estrutura, o aluno deve observar que o número de giros que o motor der será o mesmo número de giros sofridos pela engrenagem de 24 dentes, visto que estão ligados pelo mesmo eixo, portanto, tendo um descolamento apenas angular, em relação ao giro do motor. E essa relação, conforme visto anteriormente, pode ser representada como uma função linear identidade, onde seja $x$ o número de giros do motor e $f(x)$ o número de giros da engrenagem de 24 dentes, resultando então na função $f_{1}(x)=x$, com fator de proporcionalidade $a=1$.

- Para a segunda estrutura, pode-se utilizar da mesma ideia da primeira em relação à engrenagem de 8 dentes ligada ao motor pelo mesmo eixo. Conforme já visto, essa relação é representada por uma função identidade, e também já foi mencionado neste trabalho que, em se tratando de composições entre funções, quando se trata de uma função identidade, esta não altera a função que está sendo composta com ela, portanto, não se faz necessária a sua consideração nesta e tampouco nas demais estruturas, ao compor as funções. Analisando-se, então, apenas a interação entre a função de 8 dentes e a de 24, temos uma relação de proporcionalidade entre as duas, na qual ocorre uma redução de giros da de 8 para a de 24 , visto que o fator de proporcionalidade entre elas é de $1 / 3$. E, assim, a referida interação considerando o giro do motor, que será o mesmo da engrenagem de 8 dentes, e a quantidade de giros sofrida pela engrenagem de 24 , é modelada pela função linear, $f_{2}(x)=\frac{1}{3} x$, com fator de proporcionalidade, $a=\frac{1}{3}$.

- Para a terceira estrutura, já será necessário que o aluno se utilize de composição de funções, não sendo imprescindível considerar as relações de identidade, mas as interações ocorridas; duas vezes neste caso, entre uma engrenagem de 8 dentes e uma de 24. Portanto, para determinar a função linear que modela a quantidade de giros que a última engrenagem do trem de engrenagem (considerando o sentido partindo do motor) sofre, em relação aos giros dados pelo motor, será necessário fazer a composição de duas funções lineares idênticas, de fatores de proporcionalidade iguais a 1/3. E, assim, fazendo-se as devidas composições e denominando de $f_{3}$ a função modeladora desta terceira estrutura, teremos a função $f_{3}(x)=\frac{1}{9} x$, com fator de proporcionalidade, $\quad a=\frac{1}{9}$.

- Para a quarta estrutura, o caminho inicial é o mesmo da terceira, apenas ao final deverá ser feita mais uma composição com a mesma função linear de fator de proporcionalidade também igual a 1/3. Denominando-se, então, a função composta que modela a relação da quantidade de giros sofridos pela última engrenagem de 24 dentes deste sistema, com a quantidade de giros do motor, de $f_{4}$, sendo a função, $f_{4}(x)=\frac{1}{27} x$, com fator de proporcionalidade $a=\frac{1}{27}$.

Após o entendimento das interações em cada estrutura de forma separada, devese propor aos alunos a construção de uma única estrutura contendo as quatro interações. 
É necessário ressaltar que ter construído as quatro de forma separada foi oportuno por facilitar a análise de cada interação e suas modelagens por funções, mas em casos nos quais a maioria dos alunos já apresentem afinidade com construções utilizando Kits da LEGO $^{\circledR}$, a forma contendo as quatro interações já pode ser construída de forma direta, pois é o objetivo final desta parte da sequência. O modelo sugerido a ser construído com as quatro interações segue abaixo (Figuras 17 e 18):

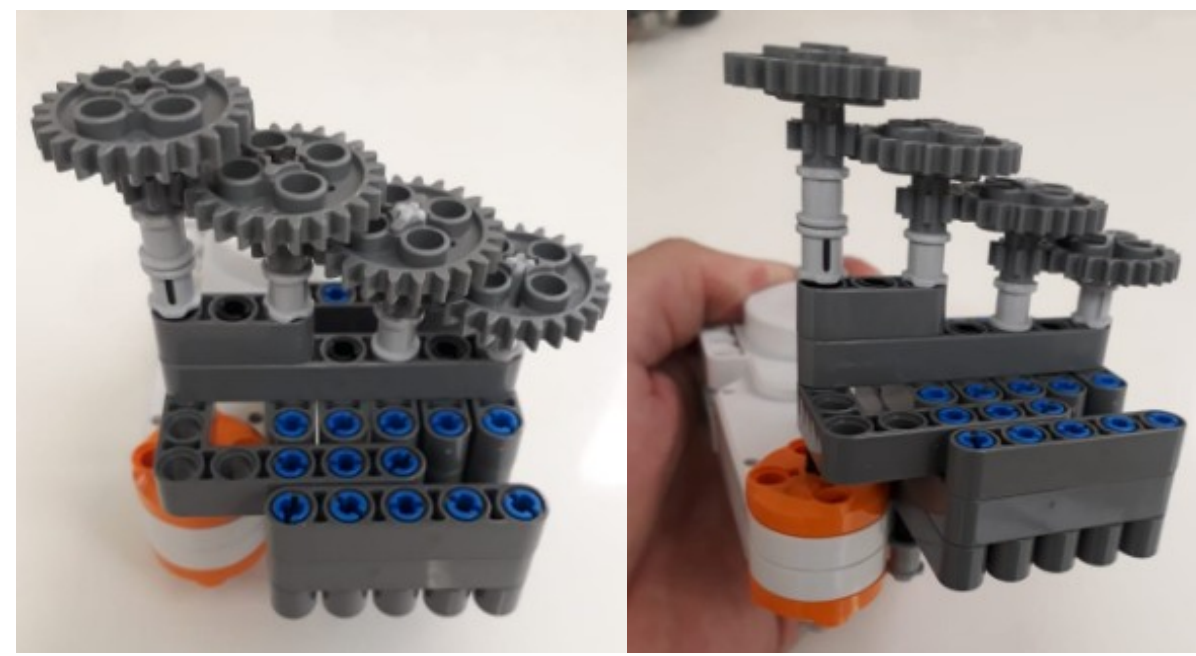

Figura 17 e 18: Motor de rotação com engrenagens acopladas, perspectivas superior e frontal respectivamente, KIT LEGO®.

Fonte: dos autores.

De posse da estrutura, deve ser acordado com os alunos que as posições de cada engrenagem de 24 dentes serão consideradas no sentido do motor dessa forma, a primeira será a primeira a partir do motor e, assim, sucessivamente. Enumerando então as quatro engrenagens de 24 dentes, formamos a PA $(1,2,3,4)$, com quatro elementos, com primeiro termo e razão iguais a 1 . Em seguida deve-se formar outra sequência, colocando para cada engrenagem de 24 dentes o fator de proporcionalidade da função que modela a relação de seus giros em função dos giros do motor. E, desse modo, teremos a sequência (1,1/3,1/9,1/27), uma PG, de primeiro termo igual a 1 e razão 1/3. É importante reforçar para os alunos a correspondência bem definida entre os termos da PA e da PG, mostrando que a cada interação, em que se adiciona ao trem de engrenagens mais uma de 8 dentes, e a esta mais uma de 24 , o número de giros sofridos pela nova engrenagem de 24 , em relação aos giros do motor, é dividido por 3 . Por exemplo, seguindo o mesmo modelo de interação, para a quinta engrenagem de 24 dentes teremos uma redução de giros em relação ao motor de 1/81, e assim por diante. É preciso fazer com que os alunos percebam, também, que essas interações podem ser feitas infinitas vezes, desde que haja peças disponíveis para isso, e que a redução a cada interação se torna mais intensa, uma característica da função exponencial, que apresenta crescimentos ou decréscimos "explosivos", e ainda que, por mais que se façam sucessivas reduções, nunca será alcançado exatamente o número zero.

É necessário também fazer atividades com os alunos explorando as PA's e PG's formadas, por exemplo, encontrando-se o termo correspondente da PG para determinado termo da PA, e vice-versa, fazendo assim com que os alunos consigam elaborar a fórmula 
do termo geral da PG. Quanto ao termo da PA, não se faz muito necessário, devido ao fato de a PA ser 1, mas também não é empecilho caso seja considerado importante. Mesmo que às vezes não haja engrenagens suficientes para montar outro trem como o do exemplo, também é possível simular exercícios, trabalhando a abstração do conceito. Por exemplo: Caso sejam substituídas todas as engrenagens de 8 dentes do sistema, por engrenagens de 12 dentes, e o sistema passe a ter um total de 7 interações, ou seja, 7 engrenagens de 24 dentes, responda:

a) A redução de giros de uma engrenagem de 24 dentes para a próxima, neste caso, será na razão de quanto? Resolução: Como agora o fator de proporcionalidade é calculado pela fração 12/24, temos assim um fator igual a 1/2. Ou seja, a razão da redução de giros da engrenagem de 24 dentes para a próxima será de 1/2.

b) Considerando-se, agora, a nova razão de redução de giros e o sistema com 7 engrenagens, qual a PA e a PG agora formadas? Resolução: PA (1, 2, 3, 4, 5, 6, 7) e PG $(1,1 / 2,1 / 4,1 / 8,1 / 16,1 / 32,1 / 64)$.

c) Considerando-se a nova PG formada, qual sua fórmula do termo geral? Resolução: Forma do termo geral de um PG: $a_{n}=a_{1} \cdot q^{n-1}$. Portanto: $a_{n}=1 \cdot\left(\frac{1}{2}\right)^{n-1}=\left(\frac{1}{2}\right)^{n-1}$.

E assim por diante. A continuação da exploração desse exercício e/ou a criação de exercícios semelhantes, fica a critério do professor.

Uma função que transforma uma PA em uma PG é uma função do tipo exponencial, $f: R \rightarrow R, f(x)=b a^{x}$, com $b=f(0)$ e $a=\frac{f(1)}{f(0)}$.

Sendo assim, o professor deve retomar com os alunos as interações entre as engrenagens no trem composto trabalhado na aula anterior, construído utilizando as engrenagens de 24 e 8 dentes, e também destacar que a correspondência entre a PA (1, $2,3,4)$ e a PG $(1,1 / 3,1 / 9,1 / 27)$ é feita pelas interações das engrenagens, explicando, com isso, o teorema (caso considerar necessário, o professor pode demonstrá-lo) e mostrando que, neste caso específico, essas interações estão agindo como uma função que está transformando os elementos da PA em elementos de uma PG. Temos então uma abstração da função, o que é parte de nosso objetivo nesta proposta. $E$ ainda que, pelo teorema, como tal interação faz essa transformação, pode-se afirmar que esta é modelada por uma função do tipo exponencial. E, nesse momento, deve ser definida, junto aos alunos, qual função do tipo exponencial modela o específico trem de engrenagens com a relação de giros entre o motor e as engrenagens de 24 dentes.

Tal definição pode ser feita da seguinte forma: A relação entre os giros do motor e o giro de cada uma das engrenagens de 24 dentes é representada pela $P A(1,2,3,4)$, que indica com qual engrenagem estamos nos relacionando, e a PG (1, 1/3, 1/9, 1/27), que indica a razão de redução ou não de giros em cada respectiva engrenagem em relação aos giros dados pelo motor. Dessa forma, temos as correspondências:

$$
\begin{aligned}
& 1 \rightarrow 1 \\
& 2 \rightarrow \frac{1}{3} \\
& 3 \rightarrow \frac{1}{9}
\end{aligned}
$$




$$
4 \rightarrow \frac{1}{27}
$$

Em linguagem de função pelo teorema temos:

Daí,

$$
\begin{gathered}
f:\{1,2,3,4\} \rightarrow\left\{1, \frac{1}{3}, \frac{1}{9}, \frac{1}{27}\right\}, f(x)=b a^{x}, \\
f(1)=b a^{1}=b a=1 \\
f(2)=b a^{2}=b a a=\frac{1}{3}
\end{gathered}
$$

E, desse modo, temos:

$$
b a a=\frac{1}{3} \Rightarrow 1 a=\frac{1}{3} \Rightarrow a=\frac{1}{3}
$$

$$
b a=1 \Rightarrow b \frac{1}{3}=1 \Rightarrow b=3 .
$$

Portanto, a função do tipo exponencial que modela as interações, levando em consideração a redução do número de giros em cada engrenagem de 24 dentes, em relação aos giros do motor, é a função $f:\{1,2,3,4\} \rightarrow\left\{1, \frac{1}{3}, \frac{1}{9}, \frac{1}{27}\right\}, f(x)=3\left(\frac{1}{3}\right)^{x}$. E conforme o teorema apresentado por Lima (2013), podemos estender o domínio e o contradomínio para:

$$
f: R \rightarrow R+, f(x)=3\left(\frac{1}{3}\right)^{x} .
$$

Sendo assim, concluímos o processo utilizando as engrenagens e suas interações até a modelagem do tipo exponencial. Utilizando agora a própria função, o professor pode propor exercícios que explorem encontrar as reduções nas engrenagens de 24 dentes, tanto a partir da posição em que cada uma se encontra no trem de engrenagem, como da posição a partir da redução. Também podem ser propostas novas reduções ou ampliações de giros, gerando-se, assim, um amplo leque de possibilidades a serem trabalhadas, como também a representação gráfica da função, uma vez que ela é definida nos reais positivos. O professor pode analisar junto aos alunos também o fato de que a primeira engrenagem de 24 dentes não sofre redução de giros em relação ao motor. Mas é preciso questionar: e se a redução já ocorresse também para esta? Nesse caso, teríamos a PA $(1,2,3,4)$ implicando a PG $(1 / 3,1 / 9,1 / 27,1 / 81)$. Essa sutil diferença resulta na passagem de modelagem de uma função de tipo exponencial para uma tipicamente exponencial, a saber, $f: R \rightarrow R+, f(x)=\left(\frac{1}{3}\right)^{x}$. Situação que também pode ser utilizada para explicar as diferenças entre uma função exponencial e uma do tipo exponencial, trabalhando-se de forma a abstrair do câmbio de marchas também suas caracterizações, por exemplo, na função exponencial $f: R \rightarrow R+, f(x)=a^{x}$, com

$$
f(1)=a \text { e } a \neq 1 \text {. }
$$

Para a construção do câmbio escolhemos a combinação que gera uma função do tipo exponencial, pois, como pode ser observado na interação modelada por exponencial, na quarta interação já temos uma redução de giros na razão de 1/81, o que seria inviável para uma apresentação por tornar a velocidade do giro da engrenagem demasiadamente lenta. 


\section{Quinta Aula}

Nesse momento da aula, serão apresentadas aos alunos quatro situações de trem de engrenagens. É bom que as interações apresentadas a seguir sejam impressas, para que os alunos acompanhem melhor as explicações, e é importante que o professor utilize uma projeção para apresentar de maneira mais clara as interações.

As imagens serão compostas por um bloco cartesiano, com três dimensões, para o que foram produzidos cilindros que representarão engrenagens e segmentos que representarão eixos. Sempre haverá apenas três tipos, como mostra a esquerda da figura, engrenagens com 8, 16 e 24 dentes (Figura 19). Porém, devem ser analisadas apenas as engrenagens que estão no trem em tom rosa e a de saída em tom azul, pois apenas essas estarão participando dos movimentos naquele momento. No início, à esquerda, está um ponto que representa um motor, que levará uma quantidade $x$ de giros por minuto para o sistema através dos segmentos que representam eixos, e as setas em sequência representam o caminho que a interação está a seguir, apontando as reduções ou ausência delas.

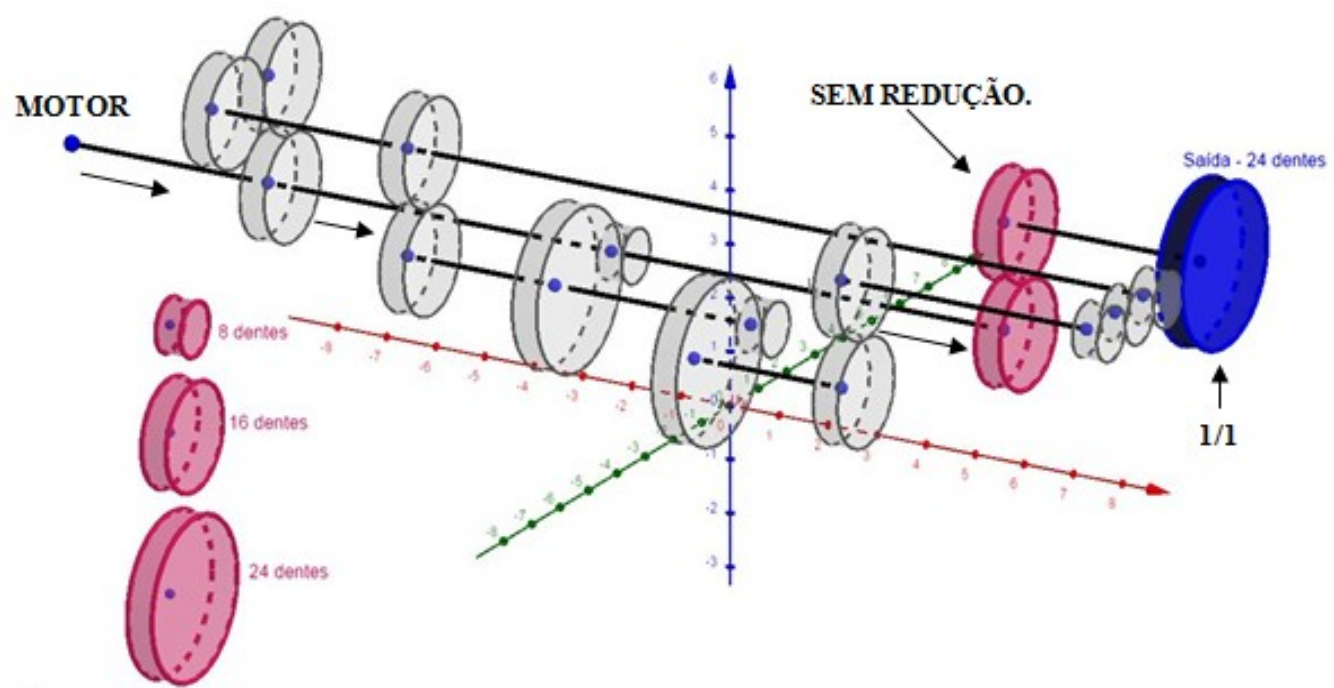

Figura 19: Primeiro trem de engrenagem - gráfico ilustrativo de trens de engrenagens elaborado no Geogebra.

Fonte: dos autores.

Nessa figura, é possível notar que o motor está ligado por um eixo (segmento) diretamente a uma engrenagem rosa, de 16 dentes. Como a ligação ocorre via eixos, não há uma redução ou ampliação do número de giros advindo do motor. E essa engrenagem, por sua vez, tem acoplada em sua parte superior outra engrenagem também de 16 dentes. Portanto, como a quantidade de dentes é a mesma nas duas, também não há alteração no número de giros. E, por fim, essa última engrenagem rosa está ligada à engrenagem azul (de saída) por um eixo, o que também resulta em nenhuma alteração na quantidade de giros. Analisando-se a situação proposta, então, de maneira geral, a quantidade de giros do motor é a mesma que chega até a engrenagem de saída (azul), ou seja, nessa combinação não tivemos nenhuma redução de giros. Matematicamente, podemos representar essa relação entre o número $x$ de giros por minuto do motor e a engrenagem de saída como uma função identidade: $f_{1}(x)=x$ 
Denotaremos por $f_{1}$ por não termos uma relação de redução ainda, considerando esta como a primeira; assim, podemos representar essa primeira combinação de engrenagens e o seu fator de proporcionalidade da função que a representa por: $1 \rightarrow 1$.

Importante: matematicamente esta será considerada como a primeira das relações. Porém, em se tratando apenas de câmbio de marchas, fazendo uma analogia com os câmbios dos automóveis, pela relação que teremos entre as quantidades de giros na engrenagem de saída, tal relação, ao final, será considerada a quarta marcha do câmbio, pois, como nas outras haverá reduções de giros, esta será a mais rápida.

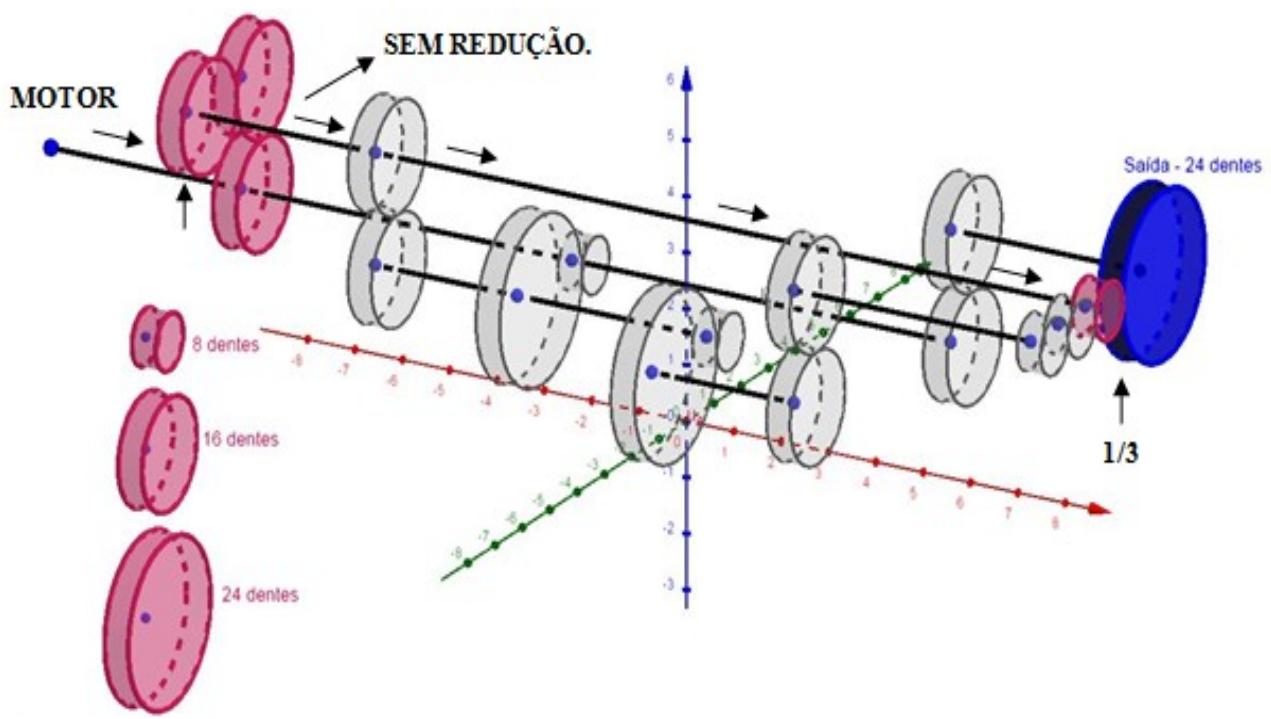

Figura 20: Segundo trem de engrenagem - gráfico ilustrativo de trens de engrenagens, elaborado no Geogebra.

Fonte: dos autores.

Na Figura 20, temos ligada diretamente ao motor por um eixo uma engrenagem de 16 dentes. Acoplada a ela em sua parte superior, outra engrenagem de 16 dentes que, por sua vez, tem ao seu lado acoplada outra engrenagem também do mesmo tipo. Sendo assim, a quantidade de giros advinda do motor até a terceira engrenagem, não sofreu alteração. A terceira engrenagem está ligada através de um eixo a uma engrenagem de 8 dentes. Como a ligação é via eixo, apesar da diferença no número de dentes, também não há alteração no número de giros. Agora, a engrenagem de 8 dentes está acoplada à engrenagem de 24 dentes de forma direta, então, nesse momento, sim, temos a primeira redução no número de giros, que, pela relação de proporcionalidade entre as duas, será de um $1 / 3$.

Portanto, matematicamente podemos representar essa relação entre o número $x$ de giros por minuto do motor e a engrenagem de saída pela função:

$$
f_{2}(x)=\frac{1}{3} x,
$$

com a relação, agora, conforme modelo da primeira de $2 \rightarrow \frac{1}{3}$. E esta também, conforme convencionado na primeira, será no câmbio a estrutura de funcionamento da terceira marcha. 


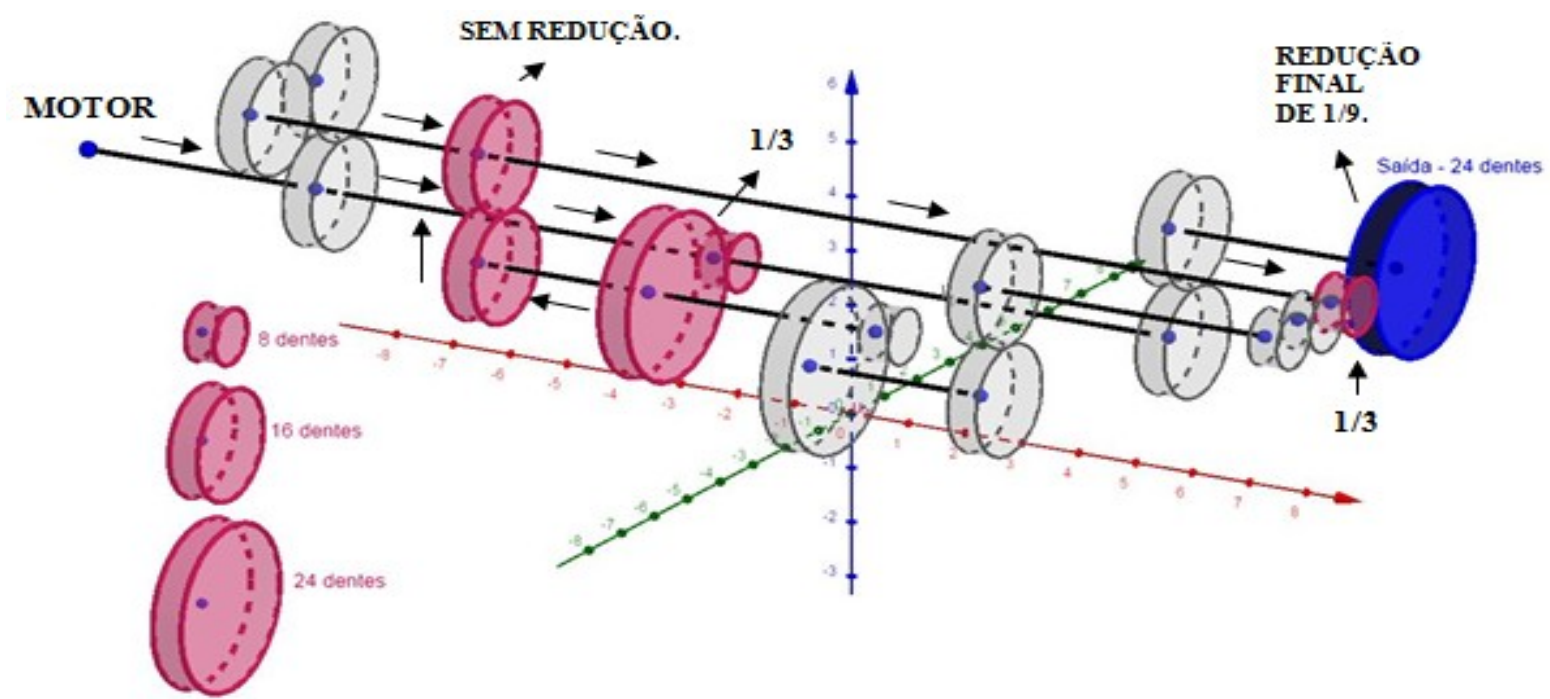

Figura 21: Terceiro trem de engrenagem - gráfico ilustrativo de trens de engrenagens, elaborado no Geogebra.

Fonte: dos autores.

Nesse trem de engrenagens, o motor está ligado via eixo a uma engrenagem de 8 dentes, portanto sem alteração no número de giros (Figura 21). Essa engrenagem está acoplada a uma de 24 dentes em sua lateral, gerando, assim, uma redução no número de giros de 1/3. Esta, de 24 dentes, está ligada a uma de 16 dentes, em sua parte traseira, via eixo, e assim, sem alteração no número de giros. Esta, por sua vez, tem acoplada em sua parte superior uma engrenagem também de 16 dentes, então, novamente, sem alteração do número de giros. A última engrenagem de 16 dentes mencionada está ligada via eixo a uma engrenagem de 8 dentes, então sem alteração no número de giros. Agora, essa engrenagem está acoplada na engrenagem de saída de 24 dentes, então, nesse momento, há mais uma redução de $1 / 3$ no número de giros, resultando, ao final (do motor até a engrenagem de saída), duas reduções de 1/3, ou seja, uma redução total de 1/9, a qual pode ser representada matematicamente (fazendo as devidas composições de funções lineares) da seguinte forma:

$$
f_{3}(x)=\frac{1}{9} x
$$

com a relação agora de $3 \rightarrow \frac{1}{9}$. E essa será a estrutura no câmbio da então considerada segunda marcha. 


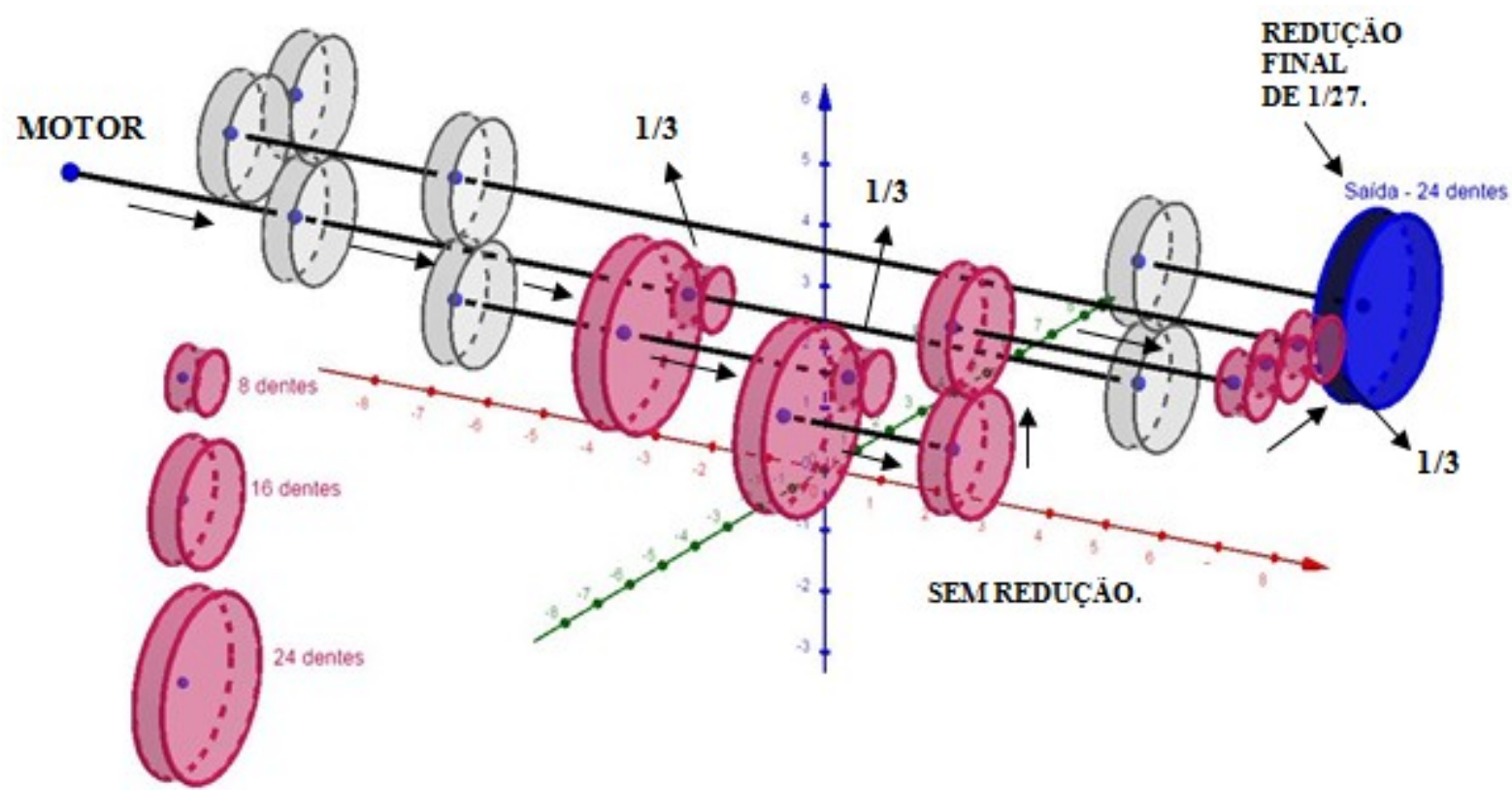

Figura 22: Quarto trem de engrenagem - gráfico ilustrativo de trens de engrenagens, elaborado no Geogebra.

Fonte: dos autores.

No quarto e último trem de engrenagem a ser apresentado, o motor está ligado via eixo a uma engrenagem de 8 dentes e, assim, sem alteração no número de giros (Figura 22). A engrenagem está acoplada a uma de 24 dentes pela lateral, portanto, com uma redução de $1 / 3$ no número de giros. A engrenagem de 24 dentes está ligada via eixo a outra engrenagem de 8 dentes, em sua parte frontal, portanto, sem alteração no número de giros. Essa engrenagem de 8 dentes mencionada está ligada a outra engrenagem de 24 dentes pela lateral, então tem-se mais uma redução de 1/3 na quantidade de giros. Essa última engrenagem de 24 dentes mencionada está ligada a uma de 16, via eixo, sendo assim, não há alteração no número de giros. Essa engrenagem de 16 dentes tem acoplada em sua parte superior outra engrenagem, também de 16 dentes, sem alteração no número de giros. Essa engrenagem de 16 dentes está ligada via eixo a outra engrenagem de 8 dentes, sem alteração no número de giros. Essa tem acopladas a sua lateral, mais duas engrenagens também de 8 dentes, sem alteração no número de giros. Agora, a última das três engrenagens de 8 dentes em sequência está acoplada à engrenagem de saída de 24 dentes, então ocorre mais uma redução de $1 / 3$. Portanto, ao final (do motor até a engrenagem de saída), temos três reduções de $1 / 3$ cada, totalizando uma redução de 1/27 no número de giros, o que pode ser representado matematicamente (fazendo as devidas composições de funções lineares) pela função:

$$
f_{4}(x)=\frac{1}{27} x,
$$

com relação de $4 \rightarrow \frac{1}{27}$. E essa é a estrutura no câmbio de marchas da primeira marcha.

Encerramos, assim, os quatro trens de engrenagens que detalham 0 funcionamento das quatro marchas do câmbio, gerando as seguintes relações (Tabela 1): 
Tabela 1: Fatores de proporcionalidade do número de giros por trens de engrenagens.

\begin{tabular}{cc}
\hline Trem de engrenagem em sequência & $\begin{array}{c}\text { Fator de proporcionalidade do número } \\
\text { de giros }\end{array}$ \\
\hline 1 & 1 \\
2 & $1 / 3$ \\
3 & $1 / 9$ \\
4 & $1 / 27$ \\
\hline
\end{tabular}

Fonte: dos autores.

Essas relações já foram vistas no início desta aula, onde foi demonstrado que podem ser modeladas pela função:

$$
f(x)=3 \cdot\left(\frac{1}{3}\right)^{x}
$$

Vale ressaltar que a progressão aritmética $(1,2,3,4)$ representa os quatro trens de engrenagens apresentados, e a geométrica $(1,1 / 3,1 / 9,1 / 27)$ representa os coeficientes das funções modeladoras de cada um desses trens. Pois, pode ficar como exercício também para os alunos, substituir a representação da progressão aritmética das sequências dos trens de engrenagens, para realmente as marchas do câmbio. Dessa forma a relação passaria a ser (Tabela 2):

Tabela 2: Fator de proporcionalidade do número de giros por marcha.

\begin{tabular}{cc}
\hline Marcha & $\begin{array}{c}\text { Fator de proporcionalidade do número } \\
\text { de giros }\end{array}$ \\
\hline Primeira & $\frac{1}{27}=\frac{1}{3^{3}}$ \\
Segunda & $\frac{1}{9}=\frac{1}{3^{2}}$ \\
Terceira & $\frac{1}{3}=\frac{1}{3^{1}}$ \\
Quarta & $1=\frac{1}{3^{0}}$ \\
\hline
\end{tabular}

Fonte: dos autores.

Assim, utilizando o mesmo processo anterior para encontrar a função modeladora dessas relações, encontramos a função:

$$
g(x)=\frac{1}{81} \cdot 3^{x}
$$

Portanto, em ambos os casos, na sequência dos trens de engrenagens ou das marchas, a função modeladora é do tipo exponencial, conforme era um dos objetivos deste trabalho. $\mathrm{E}$, ressaltando também ser importante observar que, no caso acima, se o câmbio apresentasse mais de quatro marchas, a partir da quinta haveria uma 
potencialização do número de giros na engrenagem de saída, em relação aos da engrenagem motora.

Uma atividade extraclasse consiste em entregar para os alunos os quatro trens de engrenagens e solicitar que eles informem qual será a redução final (quando houver) em relação ao número de giros do motor e à engrenagem de saída. Eles também devem apontar qual a função do tipo exponencial que modela essas relações, definindo se irão utilizar como sequência aritmética, os trens de engrenagens ou as marchas, ou até mesmo ambos.

\section{Sexta Aula}

De posse dos quatro trens de engrenagens utilizados na última aula, sejam impressos ou em slides, o professor deve corrigir possíveis erros dos alunos e explicar que cada um daqueles trens de engrenagem representa a estrutura das marchas do câmbio que será construído, o qual, ao final, será deste modelo (Figura 23):

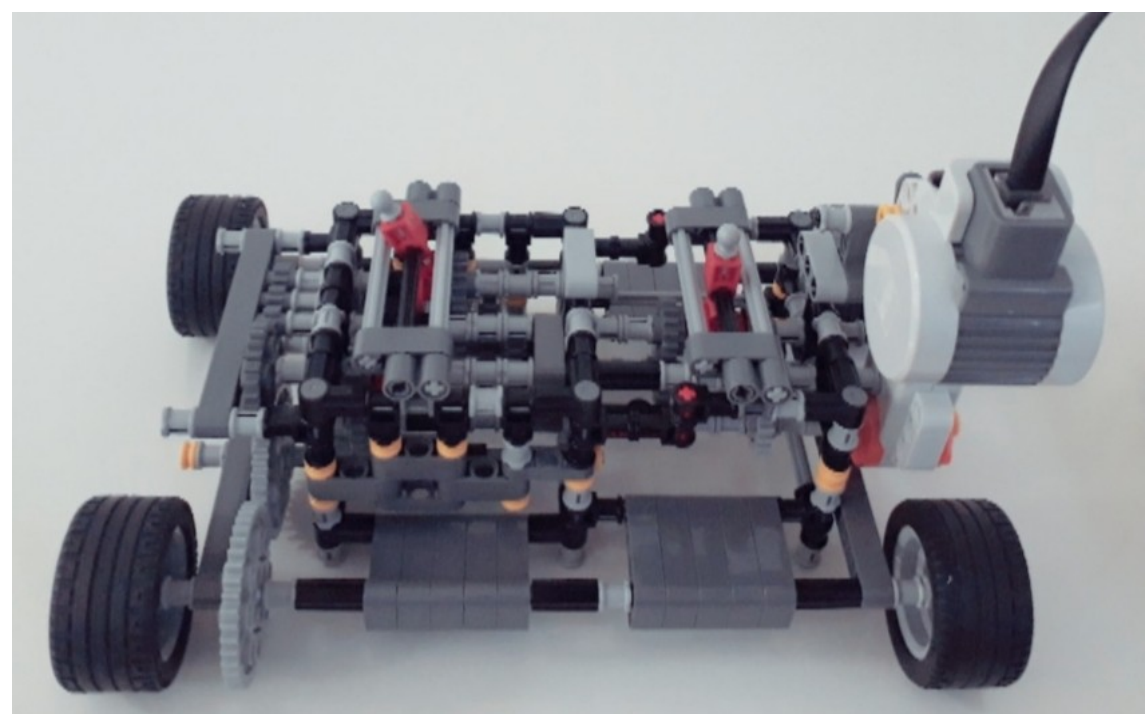

Figura 23: Câmbio de 4 marchas, produzido por peças do KIT LEGO® Mindstorms NXT. Fonte: dos autores.

No câmbio foram acrescentadas rodas, estruturas e engrenagens, mas que não interferiram em seu funcionamento exponencial, apenas contribuíram para um melhor funcionamento, e o tornaram mais atrativo aos olhos dos alunos e professores.

Nesse momento, então, o professor deve apresentar a imagem do câmbio a ser construído. É ideal que o professor já o tenha montado anteriormente para sanar qualquer dúvida no processo. Sua montagem, assim como as peças a serem utilizadas, seguem anexas ao artigo, ou podem ser acessadas no trabalho de Pires da Costa (2020), A abstração da Função Exponencial de interações entre engrenagens LEGO®. 
$\mathrm{Na}$ própria sala de aula, ou em outro espaço que seja plano, deve ser representado, no chão ou em mesas alinhadas, um plano cartesiano, onde o eixo das abscissas tenha no mínimo o intervalo de 0 a 4, e o das ordenadas, no mínimo de 0 a 9 . A unidade de medida entre as abscissas precisa ser uma que comporte, com certa folga, um carrinho na horizontal, pois ficarão alinhados. Já para a unidade entre as ordenadas, é necessário encontrar uma distância média que os carrinhos percorram durante nove segundos engatados na quarta marcha e a dividir por nove.

Para essa atividade é interessante que se tenham montado pelo menos quatro carrinhos, pois eles ficarão posicionados sobre o eixo das abscissas, sendo um carrinho na coordenada $(1,0)$, engatado na primeira marcha, outro carrinho na $(2,0)$, engatado na segunda marcha, outro na $(3,0)$, engatado na terceira, e outro na $(4,0)$, engatado na quarta marcha, conforme ilustração abaixo (Figura 24):

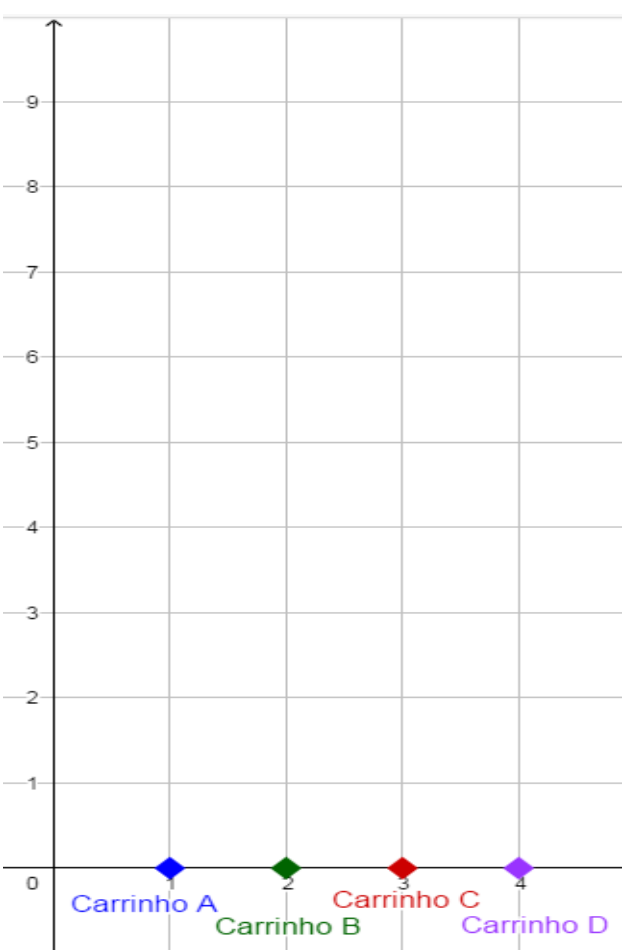

Figura 24: Gráfico deslocamento exponencial dos carrinhos, elaborado no Geogebra.

Fonte: dos autores.

Portanto, o eixo das abscissas representará a marcha engatada em cada carrinho, enquanto o eixo das ordenadas representará os segundos, após acionar o motor simultaneamente nos carrinhos. Devido às diferentes reduções ou não das marchas, à medida que o tempo $t$, em segundos, aumenta, cada carrinho vai ocupando uma posição ainda mais diferente do outro. Para iniciar a atividade, deve-se pedir que, primeiro, todos os carrinhos fiquem ligados simultaneamente durante 3 segundos. Após isso, é necessário que os alunos anotem as posições de cada um e confiram se estão de acordo com as reduções ou não de cada carrinho. Depois, eles (os alunos) devem retornar os carrinhos para a posição inicial e acionar os motores simultaneamente novamente, agora por nove segundos, e anotar novamente as posições. Os alunos devem montar, então, 
dois quadros, um para o tempo $t=3$ com suas posições e outro com $t=9$. De maneira precisa as posições dos carrinhos em cada instante serão (Figuras 25 e 26):

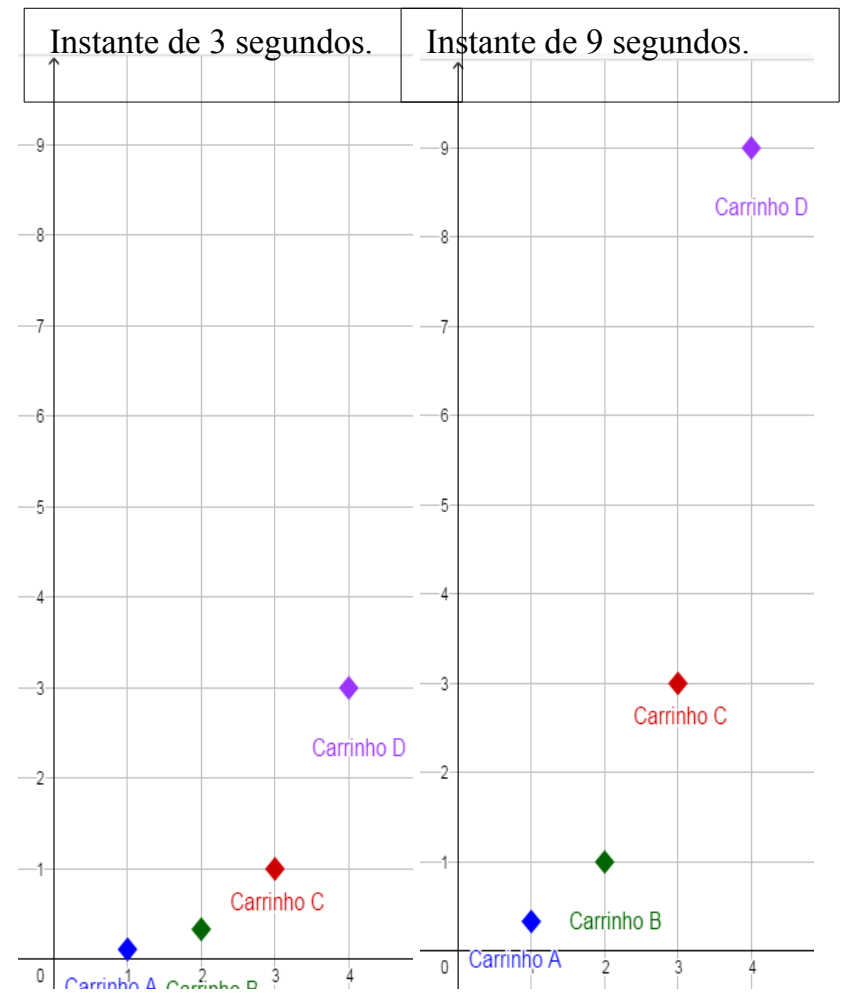

Figuras 25 e 26: Gráficos de deslocamento exponencial dos carrinhos, nos instantes 3 e 9 segundos, elaborado no Geogebra.

Fonte: dos autores.

Observando as posições no eixo das ordenadas, um exemplo de quadro a ser feito pelos alunos pode ser o seguinte (Quadro 1):

Quadro 1: Posições no eixo das ordenadas.

\begin{tabular}{|l|c|c|}
\hline \multicolumn{1}{|c|}{ Carrinhos } & No instante de 3s & No instante de 9s \\
\hline Carrinho A & $1 / 9$ & $1 / 3$ \\
\hline Carrinho B & $1 / 3$ & 1 \\
\hline Carrinho C & 1 & 3 \\
\hline Carrinho D & 3 & 9 \\
\hline
\end{tabular}

Fonte: dos autores.

Em seguida, os alunos devem ser direcionados a observar que, à medida que 0 tempo foi multiplicado por 3 , as posições também o foram, pois apresentam uma relação linear. Dessa forma, deve Ihes ser pedido que montem um quadro das posições em relação a um tempo $t$ qualquer.

Fica como resposta e sugestão de quadro o Quadro 2 a seguir: 


Quadro 2: Posições no eixo das ordenadas, no instante de t segundos
\begin{tabular}{|l|c|}
\hline \multicolumn{1}{|c|}{ Carrinhos } & Posições \\
\hline Carrinho A & $\frac{1}{27} t$ \\
\hline Carrinho B & $\frac{1}{9} t$ \\
\hline Carrinho C & $\frac{1}{3} t$ \\
\hline Carrinho D & $1 t$ \\
\hline
\end{tabular}

Fonte: dos autores.

Em seguida, analise junto aos alunos que, enquanto as marchas de cada carrinho em sequência representam uma $P A$, as posições no eixo das ordenadas representam uma PG, e, assim, novamente podemos representar essa relação por uma função do tipo exponencial, dessa vez com mais um importante detalhe: com a PG estando em função do tempo decorrido em segundos $t$. Deve ser proposto, então, que os alunos encontrem a função que modela a relação. Resposta:

$$
\begin{gathered}
f(x)=b \cdot a^{x} \\
f(1)=b \cdot a^{1}=b a=\frac{1}{27} t \\
f(2)=b \cdot a^{2}=b a a=\frac{1}{9} t
\end{gathered}
$$

Daí,

$$
\text { baa }=\frac{1}{9} t \Rightarrow \frac{1}{27} t a=\frac{1}{9} t \Rightarrow a=3 .
$$

Assim:

$$
b a=\frac{1}{27} t \rightarrow b \cdot 3=\frac{1}{27} t \rightarrow b=\frac{1}{81} t=\frac{t}{81}
$$

Portanto, a função do tipo exponencial que modela a relação do tempo $t$ decorrido e a posição do carrinho em relação ao eixo das ordenadas é:

$$
f: R \rightarrow R+, f(x)=\frac{t}{81} \cdot 3^{x}, t \in R+,
$$

onde $x$ representa a marcha engatada em cada carrinho com sua posição na horizontal e $f(x)$ a posição em que o carrinho estará a cada instante $t$ de segundos decorridos.

Utilizando a função que modela a posição de cada carrinho em relação ao eixo das ordenadas, o aluno deve calcular primeiramente, no caderno, qual a posição de cada um dos quatro carrinhos no instante de 6 segundos e, depois de feito isso, conferir as posições utilizando os próprios carrinhos, cronometrando o tempo de seis segundos. Resposta: Seja a função que modela tal relação:

$$
f: R \rightarrow R+, f(x)=\frac{t}{81} \cdot 3^{x}, t \in R+,
$$


Para o instante $t=6$ temos:

$$
f: R \rightarrow R+, f(x)=\frac{6}{81} \cdot 3^{x}
$$

Dessa forma, a posição de cada carrinho será:

Carrinho A - Primeira marcha: $f(1)=\frac{2}{27} 3^{1}=\frac{6}{27}$.

Carrinho B - Segunda marcha: $f(2)=\frac{2}{27} 3^{2}=\frac{18}{27}=\frac{2}{3}$.

Carrinho C - Terceira marcha: $f(3)=\frac{2}{27} 3^{3}=\frac{54}{27}=2$.

Carrinho D - Quarta marcha: $f(4)=\frac{2}{27} 3^{4}=\frac{162}{27}=6$.

A seguir, os alunos devem conferir com os próprios carrinhos as respectivas posições, decorridos os seis segundos. A Figura 27 mostra o gráfico da função exponencial da atividade.

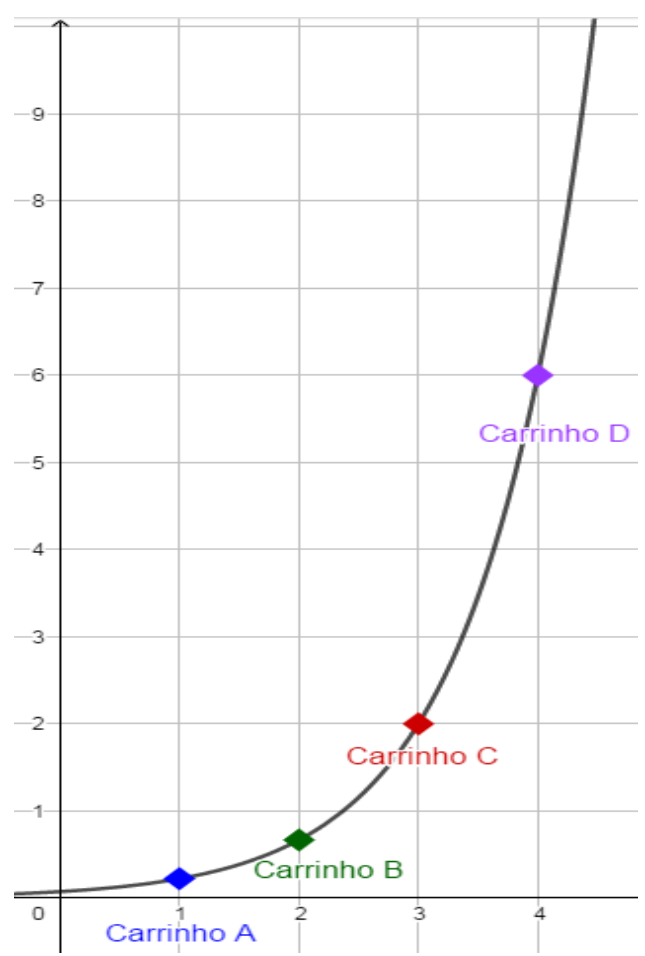

Figura 27: Gráfico da função exponencial que modela o deslocamento dos carrinhos, elaborado no Geogebra.

Fonte: dos autores.

Com o término desta sequência didática, é esperado que os alunos tenham assimilado - utilizando como modelos as interações entre engrenagens e o carrinho - a caracterização de uma função exponencial e do tipo exponencial, como também o seu tipo de crescimento e decréscimo, e que funções injetivas que transformam uma PA em uma PG, ainda que de forma discreta, são funções exponenciais ou do tipo exponencial. 
Também é esperada uma melhora quanto às atitudes relacionadas ao trabalho em equipe, como cooperação e respeito.

\section{Considerações finais}

Vimos a possibilidade de modelar os giros das engrenagens, por uma função exponencial ou do tipo exponencial, em que as razões de proporcionalidade entre específicas engrenagens no sistema formarão em sequência uma PG que, de acordo com os Teoremas de Caracterização de Função Exponencial, apresentar-se-á como recurso no auxílio do ensino da função exponencial.

Observamos que quando nos propomos a modelar algo concreto, por conceitos matemáticos abstratos, aproximamos a matemática presente no mundo teórico da presente no mundo real, o que nos faz interiorizar tais conhecimentos de uma forma sólida. Como corrobora Piaget (1978), utilizamos modelos já interiorizados em nosso intelecto para assimilar e acomodar novos modelos advindos da relação com objetos do meio. E quando essa interiorização é acompanhada de afetividade, ela é efetivamente significativa (PAPERT, 1985).

Portanto, concluímos que as engrenagens e suas interações, como apontou Papert (1985), são ótimas para serem modeladas por conceitos matemáticos, e, através dessa abstração, excelentes objetos de estudo a serem utilizados no ensino desses conceitos abstraídos.

\section{Referências}

BRASIL. Base Nacional Comum Curricular: Ensino Médio. 2017. Disponível em: http://portal.mec.gov.br/conselho-nacional-de-educacao/base-nacional-comum-curricularbncc-etapa-ensino-medio. Acesso em: 02 out. 2019.

BENITTI, F. B. V. et al. Experimentação com robótica educativa no ensino médio: ambiente, atividades e resultados. In: Anais do Workshop de Informática na Escola. Blumenau: Departamento de Sistemas e Computação Universidade Regional de Blumenau, 2009. Disponível em: https://www.brie.org/pub/index.php/wie/article/view/2166. Acessado em: 22 out. 2018.

LEGO GROUP. Linha cronológica da origem e evolução da empresa. 2010. Disponível em: https://www.lego.com/pt-br/aboutus/lego-group/thelegohistory. Acesso em: 01 nov. 2019.

LIMA, E. L. Números e Funções Reais. 1. Ed. Coleção PROFMAT SBM. Rio de JaneiroRJ. 2013.

MORELATO, L. A.; NASCimento, R. A. de O.; D' ABREU, J. V. V.; BORGES, M. A. F. Avaliando diferentes possibilidades de uso da Robótica na Educação. Revista de Ensino de Ciências e Matemática, REnCiMa, v. 1, n. 2, p. 80-96, 2010. 
PAPERT, S. Constructionism versus instructionism. 1980. Disponível em: http://www.papert.org/articles/const inst/const inst1.html. Acesso em: 1 jul. 2020.

PAPERT, S. LOGO: Computadores e Educação. Trad. José Armando Valente, Beatriz Bitelman, Afira Vianna Ripper. São Paulo: Editora Brasiliense, 1985.

PIAGET, J. A Construção do Real na Criança. Rio de Janeiro: Zahar, 1975.

PIAGET, J. Psicologia e epistemologia: Por uma teoria do conhecimento (A. Cretella, Trad.). Rio de Janeiro: Forense Universitária. (Trabalho original publicado em 1957), 1978.

PIRES DA COSTA, C. A abstração da função exponencial de interações entre engrenagens $L E G O^{\circledR}$. 2020. 196f. Dissertação (mestrado em matemática), Universidade Federal de Goiás, Regional Catalão, Departamento de Matemática, 2020.

SILVA, A. A. $O$ Ensino de Funções Lineares: uma abordagem Construtivista/Construcionista por meio do Kit LEGO ${ }^{\circledR}$ Mindstorms. 2014. $61 \mathrm{f}$. Dissertação (mestrado em matemática), Universidade Federal de Goiás, Regional Catalão, Departamento de Matemática, 2014.

ZABALA, A. A prática educativa: como ensinar. Trad. Ernãni E da F. Rosa. Porto Alegre: Artmed, 1998. 